\title{
GREEN CLOSED-LOOP SUPPLY CHAIN NETWORK DESIGN: A NOVEL BI-OBJECTIVE CHANCE-CONSTRAINT APPROACH
}

\author{
Amin Reza Kalantari Khalil Abad and Seyed Hamid Reza Pasandiden*
}

\begin{abstract}
In this paper, a novel chance-constrained programming model has been proposed for handling uncertainties in green closed loop supply chain network design. In addition to locating the facilities and establishing a flow between them, the model also determines the transportation mode between facilities. The objective functions are applied to minimize the expected value and variance of the total cost $\mathrm{CO}_{2}$ released is also controlled by providing a novel chance-constraint including a stochastic upper bound of emission capacity. To solve the mathematical model using the General Algebraic Modeling System (GAMS) software, four multi-objective decision-making (MODM) methods were applied. The proposed methodology was subjected to various numerical experiments. The solutions provided by different methods were compared in terms of the expected value of cost, variance of cost, and CPU time using Pareto-based analysis and optimality-based analysis. In Pareto-based analysis, a set of preferable solutions were presented using the Pareto front; then optimality-based optimization was chosen as the best method by using a Simple Additive Weighting (SAW) method. Experimental experiments and sensitivity analysis demonstrated that the performance of the goal attainment method was $13 \%$ and $24 \%$ better that of global criteria and goal programming methods, respectively.
\end{abstract}

Mathematics Subject Classification. 90-08.

Received December 19, 2019. Accepted March 5, 2021.

\section{INTRODUCTION}

The supply chain design problem consists of defining where and how to deploy assets (plants, warehouses, and distribution centers) and how flows of materials (raw materials, parts and final products) should be moved along the network of entities (suppliers, manufactures, distributors, retailers, and customers) to enhance the overall performance [40]. The goal of designing supply chain networks in early research has only been minimizing the costs. In recent years, there has been the aggravation of the environmental pollution due to different industrial activities in the developed and industrialized countries. Therefore, restrictive laws and ethical frameworks have been presented by different governments to help future generations make a proper use of the environment. Laws related to limiting the environmental damage, together with the intensification of the competitive environment between companies, in addition to the economic goals, have created a broader concept called greenness in the recent research.

Keywords. Bi-objective optimization, green closed-loop supply chain network design, chance-constrained programming, Pareto-based analysis, Lp-metrics, multi-objective decision-making.

Department of Industrial Engineering, Faculty of Engineering, Kharazmi University, Tehran, Iran.

* Corresponding author: shr_pasandideh@khu.ac.ir 
Issues such as reverse logistics, green manufacturing and remanufacturing, and waste management, as important subsets of green supply chain management, have recently received increasing attention in both academia and industry [49]. If both direct and reverse flows are considered simultaneously in a network, the resulting network is referred to as closed loop supply chain [21]. Reversing the flow of the supply chains includes the end of use (EOU), the end of life (EOL), the unused raw materials, etc. In many studies, only EOU products come back to the return flow of the supply chain. According to the new European and American laws, due to the need to increase productivity and reduce waste products, the recycling of EOL products should also be considered in supply chain design.

Apart from green technology in the design of closed-loop supply chains, handling uncertainty in a wide range of parameters should also be applied to enhance the resiliency of the decision-making process. Decision variables in network design are divided into three categories: strategic (e.g., locating, capacities, etc.), tactical (e.g., allocation, planning, etc.), and operational (e.g., order size, inventory, etc.) [12]. The cost of strategic, tactical and strategical decisions, and many other parameters in the design of networks is uncertain. There are different approaches based on the presence or absence of the historical data resulting from uncertain parameters for modelling uncertainties. Uncertainty modelling methods include fuzzy programming [13], stochastic scenario based programming [30], chance-constrained programming [43], robust optimization [19], and hybrid methods such as fuzzy-stochastic programming or stochastic-possibilistic programming [17].

In addition to choosing the right method to control uncertainties, another important factor is the correct selection of the parameters for uncertainty modelling. Some parameters include market demands and product prices [11] costs parameters and demands [16] demands demands supplies processing time transportation shortage capacity expansion costs [4] cost parameters and demand fluctuations [36], total available production time for plants setup and operation times to produce products and all cost parameters [3]. These are selected by researchers to control the involved uncertainties. An important issue in the modelling approach is the selection of new uncertain effective parameters to best control of model uncertainties.

In this work, a four-level green closed loop supply chain has been developed. This supply chain includes factories that produce and reproduce the product, storehouses that control and store products from factories, customers that are the final users of the products, and disassembly centers that collect waste products from customers and return them to the direct current after assembly. In the current green supply chain, greenhouse gas emissions are controlled by the stochastic upper bound of the emission capacity, which is determined by governments and regulatory bodies. The main goal of the design is to determine the location of the facility, allocate the appropriate flow, and determine the appropriate transportation method between facilities to reduce the costs and emissions of the greenhouse gases. The model was first formulated as a single-objective stochastic mixed integer linear model.For the first time, the costs, the upper bound of the emission capacity, the minimum percentage of the units of product to be disposed and collected from a customer, and the minimum percentage of the units of product to be dismantled and shipped from a disassembly center (DC) were considered uncertain. The resulting model, with the chance constraints for changing from a stochastic mode to a deterministic one, became a two-objective nonlinear integer one. The first objective was minimizing the total expected value of costs; the second one was minimizing the total variance of the costs. Then, to solve the model, four MODM methods were used. These methods were carefully evaluated using Pareto-based and optimal-based analyses based on the CPU time and the solution quality. The main contribution of the present study, addressing the existing gaps, is as follows:

Modelling perspective: The novelties of the modelling approach include:

(1) For the first time, uncertainties in green closed-loop supply chain networks are modeled using a hybrid probabilistic chance-constrained programming and cost function.

(2) This is the first research that considers all features including closed-loop, greenness, determination of the transportation method with cost and environmental concerns, and the uncertainty issue for a wide range of critical parameters in the design of green closed-loop supply chain.

(3) This study assumes new parameters with uncertainty that are not found in the literature. 
Solution method and sensitive analysis approach: The novelties of the present study, in comparison with the recent research on solution methodology and sensitive analysis, include the following:

(1) Although there are some studies comparing different MODM solution methods [18], this is the first study comparing four MODM methods including $\varepsilon$-constraint, Lp-metrics, Goal programming, and Goal attainment in the design of green closed loop supply chain network.

(2) A comprehensive analysis was conducted. To help the decision maker in the decision-making process, in addition to generating efficient solutions using the Pareto front (Pareto-based analysis), the solutions obtained from the three MODM methods were compared and the best solution was selected in terms of three critical indicators (Optimality-based analysis).

Here are the questions of research of the paper:

(1) Which potential facilities should be activated?

(2) How much material flow should be transferred between established facilities?

(3) How the transportation mode could be determined between each of the actived facilities?

(4) What are the environmental impacts of the supply chain and how are they calculated and bounded?

(5) How the fluctuations of fundamental uncertain parameters could be controlled?

(6) How to provide a set of effective solutions for a multi-objective model using exact methods?

(7) How different exact methods could be compared for solving a multi-objective models?

The structure of the present study is organized as follows; Section 2 is a review of the past studies and the existing literature gaps. Section 3 describes the hypotheses, goals and problem applications in the real world, sets, parameters and decision variables. Further, it introduces the single-objective linear probabilistic model and the multi-objective non-linear deterministic one. Section 4 examines various MODM methods used to solve the model. Finally, Section 5 compares various MODM methods by some numerical experiments to select the best method by the decision maker.

\section{Literature REVIEW}

Network design has been one of the most attractive fields for researchers. The development of supply chain design model hypotheses is of particular importance in moving towards reality. Therefore, the review of the previous research in this section is based on various assumptions made in recent studies. First, those studies on network design that have not considered green technology and control of uncertainties have been reviewed. Then, green network design studies and finally, green network design studies along with modelling uncertainties have been reviewed. At the end, the recent studies concerned with modelling different uncertain parameters have also been discussed.

\subsection{Supply chain design}

Many researchers have been designing supply chain networks. Atiparmark et al. [3], for instance, have designed a supply chain using the multi-objective programming approach. They have used a new method based on the Genetic Algorithm (GA) to solve problem; for the numerical testing of the model, they applied actual data at a plastic manufacturing plant in Turkey. Liu et al. [33] have also presented a multi-objective mixed integer linear programming (MILP) approach to model production, distribution, and capacity planning for a global supply chain. They have considered the objectives of costs, responsiveness, and the customer service level in the model; they have also used the methods of $\varepsilon$-constraint and Pareto-based analysis to solve problem. Further, Alshamsi and Diabat [2] have presented a mixed integer linear programming model for the reverse logistics design. Their model could consider options for the transportation of components using the internal fleet as well as outsourcing options. Further, Bottani et al. [7] have provided a bi-objective mixed integer linear programming model for a multi-product resilient food supply chain network. Their goals in designing the model were to maximize the total profit and to minimize the total supply chain lead-time. To solve the model, the adapted Ant Colony Optimization (ACO) algorithm was tested based on a real case study. 


\subsection{Closed-loop supply chain design}

The growing environmental and social concerns around the world have led many researchers to design supply chain networks with reverse flow to reproduce and recycle products. Özceylan et al. [41] have proposed a linear programming model to design a closed-loop supply chain network for end-of-life vehicles. Their proposed model has been evaluated based on the real study of an automotive industry in Turkey. Zohal and Soleimani [59] have also developed a multi-objective single product model for designing a green closed-loop gold supply chain network. The first objective of their model was to minimize total costs and the second one was to minimize greenhouse gas emissions. They have used a novel ACO algorithm to solve the model. Khatami et al. [32] also proposed a Benders decomposition algorithm for the problem of designing a multi-product, multi-product closed-loop supply chain network. They have used Cholesky's factorization and k-means clustering methods to generate a scenario based on the demand distribution function. Nurjanni et al. [40] have also proposed a new multi-objective model for designing a sustainable closed-loop supply chain. Their model, in addition to the EOU products, also included EOL products in the return flow. They also used three different scalarization methods to transform their two-objective model into a single objective one and provided the Pareto-optimal set. Further, Samuel et al. [50] have provided a deterministic mathematical model and its robust variant to design a closed-loop supply chain network by taking into account multiple products, multiple customer zones, the quality of returns, and the effects of emission policies. They have evaluated the effects of the quality of returns on the closed loop network under carbon cap and carbon cap-and-trade policies.

\subsection{Green supply chain design}

With the growth of environmental pollutants, the imposition of international limiting laws and the need to change the structure of supply chains, the attention of researchers and companies has been drawn to the design of a network of green and sustainable supply chains. In this regard, Jamshidi et al. [29] have designed a green supply chain for economic and environmental goals. In the model provided by them, there are several options for shipping on each chain level. They have also used the Taguchi method for parameter tuning and combination of the memetic algorithm for solving their model. Mohtashami et al. [39], on the other hand, developed a nonlinear programming (NLP) model for designing a supply chain network with direct and reverse flow. They used the queuing system to optimize the transportation and waiting time of the transportation fleets' network. The exact solution methods were applied to solve the model in a small size, while meta-heuristic approach was employed to solve the model in a large size. Vasei and Polyakorskiy [54] have also provided a model for supply chain design by ng considering economic, social, and environmental dimensions of sustainability. They have solved two mixed integer linear models with the $\varepsilon$-constraint method by CPLEX. Mardan et al. [34] also designed a multi-product, multi-product green closed-loop supply chain network. They used the Lp-metric method to convert the multi-objective model into a single-objective one. An accelerated Benders algorithm was used to solve the large-scale model.

\subsection{Green supply chain design under uncertain environment}

Network design is complete when uncertainties are handled in decisions. Some researchers, assuming no historical data regarding their indeterminate parameters of models, have considered the fuzzy programming method to control uncertainties. Paksoy et al. [42] have also presented a fuzzy multi-objective model for designing a green supply chain network. They used the analytic hierarchy process (AHP), fuzzy AHP (F-AHP), and fuzzy TOPSIS (F-TOPSIS) approaches for numerical testing to help decision makers. Mohamed and Wang [38] have also provided a four-objective model for designing a green supply chain network. They used fuzzy programming to model uncertainties. Accordingly, the LP-metrics method, the $\varepsilon$-constraint method, and the goal programming method were applied to solve the model; also, the use was made of the Max-Min method to select the best solution. Fakhrzad and Goodarzian [13] have proposed a fuzzy multi-objective programming model for designing a multi-product and multi-period green closed-loop supply chain network. The objectives of their model included minimizing the total cost and the gas emissions costs, and improving the reliability of 
the delivery demand. They used a modified version of the Imperialist Competitive Algorithm (ICA) to solve the resulting model. Researchers have also used probabilistic programming methods such as robust optimization, scenario-based programming, chanced-constrained programming, and hybrid methods to model uncertainty when historical data is available for their uncertain parameters. Further, Rezaee et al. [46] have designed a green open-loop loop supply chain network with a carbon trading scheme. They have assumed demand and carbon prices as uncertain and used two-stage stochastic scenario-based programming to control uncertainties. Yavari and Geraeli [56] have also developed a mixed-integer linear model for designing a closed-loop green supply chain that used robust optimization to control uncertainty in demand, return rates, and quality of the return products. In addition, Keyvanshokooh et al. [31] have proposed a new model for designing a closed loop supply chain. In their model, transportation costs have been modeled using stochastic scenarios; demand and returns have been modeled using robust optimization. Zhen et al. [58] have provided a bi-objective optimization model for designing a green and sustainable closed-loop network. They used a two-stage stochastic scenariobased programming approach to model the demand uncertainty. They have developed the Lagrangian-Relaxian method to solve the model. Further, Pasandideh et al. [43] have presented a multi-objective non-linear model for designing an open loop supply chain in which costs, the customer's demand, production time, and set-up time were considered uncertain. They used the chance-constrained method to model uncertainty. According to the literature related to supply chain network design, there is no previous research based on possibilisticprogramming (hybrid chance-constrained programming and cost function) to design green and sustainable closed-loop supply chain networks.

In addition to selecting the appropriate method for uncertainty modelling, selecting the most effective parameters with uncertainty is also very important. Previous studies have assumed various parameters with uncertainty. Table 1 illustrates these parameters.

Table 1 describes the first research gap covered by the present research. Previous studies have mainly assumed the demand, costs, time, supply, etc. to be uncertain. Meanwhile, in the design of green closed-loop supply chain networks, the parameters causing the return flow and the upper bound of greenhouse gases emission are the important sources of fluctuations in decisions. Therefore, this study, for the first time, considers the uncertainty in the most sensitive parameters of the model, namely, cost parameters, the minimum percentage of the units of product to be disposed and collected from a customer, the minimum percentage of the units of product to be dismantled and shipped from a $\mathrm{DC}$, and the upper bound of total $\mathrm{CO}_{2}$ released, simultaneously.

Table 2 represents the research gaps in the previous studies from another perspective. According to this table, researchers have not applied the hybrid probabilistic chance-based constrained programming and cost function approach to the design of green closed-loop supply chain network. Also, no study has considered all features including closed-loop, greenness, determination of the transportation method with cost and environmental concerns, and the uncertainty issue for a wide range of critical parameters in the design of green closed-loop supply chain. Accordingly, the present study has considered all these mentioned features and presented a new approach based on stochastic chance-based constrained programming. So, previous studies have not examined different MODM methods in multi-objective green closed-loop supply chain network design problems. Another contribution of this study is the comparison of three different MODM methods and the formation of the Pareto front using the Lp-metric method.

\section{Problem Description AND ASSUMPtions}

In this problem, four different levels for supply chain, including the factory $I$, the warehouse $J$, the customer $K$ and $L \mathrm{DC}$, are considered. Figure 1 shows the structure of the green supply chain studied.

The goals of the design of such a network include: (1) covering the customer's deterministic demand, (2) locating facilities, (3) establishing an appropriate flow of facilities, (4) choosing the best transportation method among components, (5) controlling greenhouse gas emissions, (6) controlling disposal products and returning them to the direct current through disassembly and recovery, and (7) controlling the uncertainty of effective parameters for more realistic modelling. The proposed model can be used to design complex networks of global 
TABLE 1. Summary of uncertain modelling methods and uncertain parameters in the literature.

\begin{tabular}{|c|c|c|}
\hline Authors & Methods of uncertainty modelling & Uncertain parameters \\
\hline $\begin{array}{l}\text { Ruiz-Femenia et al. } \\
\text { [48] }\end{array}$ & Stochastic scenario-based & Demand \\
\hline $\begin{array}{l}\text { Mirzapour Al-e- } \\
\text { hashem et al. }[36]\end{array}$ & Robust optimization & Costs and demand fluctuations \\
\hline Guillena et al. [22] & Two-stage stochastic programming & Production \\
\hline Azaron et al. [4] & Stochastic programming & $\begin{array}{l}\text { Demands, supplies, processing time, and } \\
\text { costs }\end{array}$ \\
\hline Hnaiena et al. [25] & Stochastic programming & Lead time \\
\hline Song et al. $[51]$ & $\begin{array}{l}\text { Hybrid Possibilistic and stochastic pro- } \\
\text { gramming }\end{array}$ & $\begin{array}{l}\text { Material supplies, production times, and } \\
\text { demands }\end{array}$ \\
\hline Zhang et al. [57] & $\begin{array}{l}\text { Hybrid fuzzy and Possibilistic program- } \\
\text { ming }\end{array}$ & Price and demand \\
\hline Rezaee et al. [46] & Two-stage scenario-based programming & Demand and carbon price \\
\hline Zhen et al. [58] & $\begin{array}{l}\text { Two-stage stochastic scenario-based pro- } \\
\text { gramming }\end{array}$ & Demand \\
\hline $\begin{array}{l}\text { Mohammed and } \\
\text { Wang [38] }\end{array}$ & Fuzzy programming & Supply capacity and demand \\
\hline Imran et al. [28] & Fuzzy programming & Product complaints \\
\hline Badri et al. [5] & Two-stage stochastic programming & $\begin{array}{l}\text { Demands and the maximum available } \\
\text { number of cores in each customer zone }\end{array}$ \\
\hline Qu et al. [45] & $\begin{array}{l}\text { Robust optimization (basis Monte Carlo } \\
\text { simulation) }\end{array}$ & $\begin{array}{l}\text { Structural design parameters (shaping di- } \\
\text { mensions positioning dimensions and } \\
\text { radius) }\end{array}$ \\
\hline $\begin{array}{l}\text { Heidari-Fathian and } \\
\text { Pasandideh [23] }\end{array}$ & Robust optimization & Supply and demand for blood products \\
\hline $\begin{array}{l}\text { Yavari and Geraeli } \\
{[56]}\end{array}$ & Robust optimization & $\begin{array}{l}\text { Demand, rate of return, and quality of the } \\
\text { return products }\end{array}$ \\
\hline $\begin{array}{l}\text { Al-Juboori and } \\
\text { Datta [1] }\end{array}$ & Multi-objective stochastic programming & Heterogeneous hydraulic conductivity \\
\hline Pasandideh et al. [43] & $\begin{array}{l}\text { Possibilistic programming (hybrid chance- } \\
\text { constraint and cost function) }\end{array}$ & $\begin{array}{l}\text { Costs,demand, production, and set-up } \\
\text { times, }\end{array}$ \\
\hline This paper & $\begin{array}{l}\text { Possibilistic programming (hybrid chance- } \\
\text { constraint and cost function) }\end{array}$ & $\begin{array}{l}\text { Costs, upper bound of the emission capac- } \\
\text { ity, minimum percentage of the units of } \\
\text { product to be disposed and collected from } \\
\text { a customer, and the minimum percentage } \\
\text { of the units of product to be dismantled } \\
\text { and shipped from a DC }\end{array}$ \\
\hline
\end{tabular}

supply chains, large-scale supply chain networks such as petrochemicals, petroleum and automobiles, and various types of small and medium-sized industries.

The assumptions of the problem are as follows:

(1) The model is single-period and single-product.

(2) The time period of strategic (long-term) and tactical (medium-term) decisions is assumed to be large enough in the model, such that the lag between forward and backward supply chain is included in its framework.

(3) Customer demand is definitive.

(4) Shortage is allowed for all customer demands. 


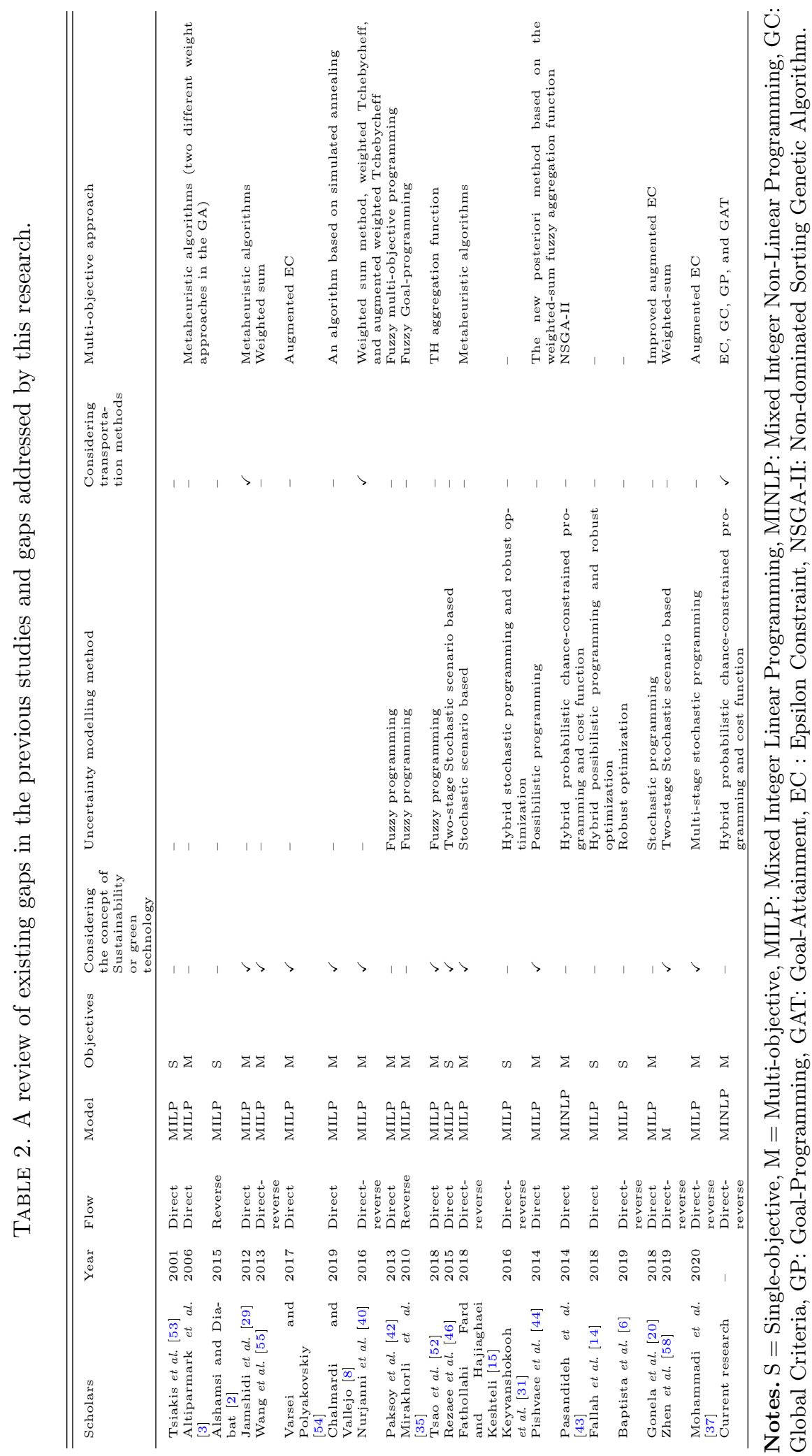




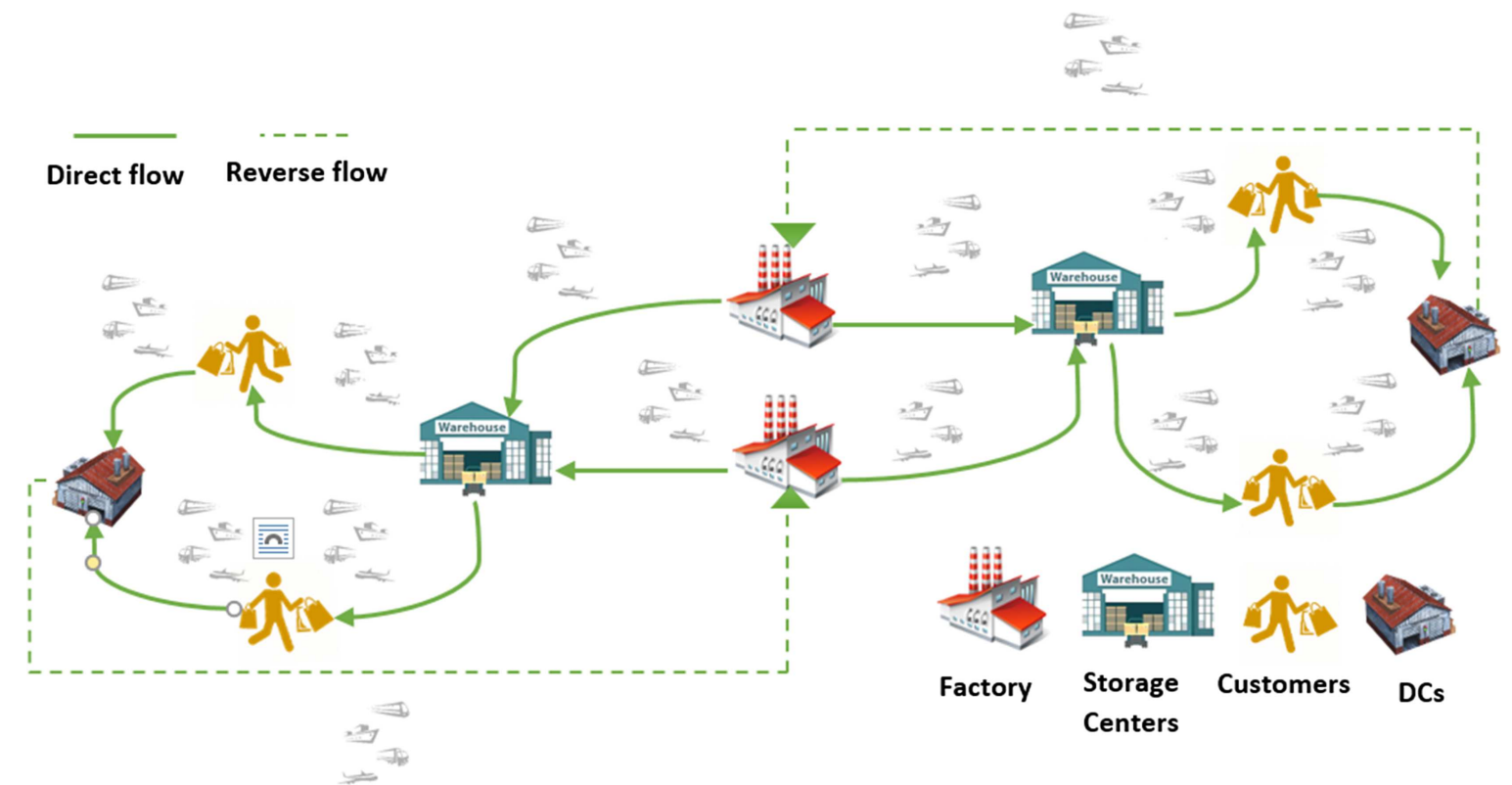

FigURE 1. The structure of communication along with various transportation methods among various facilities in the green supply chain network.

(5) All cost parameters, the upper bound of the emission capacity, and the minimum percentage of the units of product to be disposed and collected from a customer and to be dismantled and shipped from a DC are assumed with uncertainty.

(6) All uncertain parameters are assumed to have a normal distribution.

(7) For transportation between facilities, several options including sea, land, air, rail, etc. are assumed.

The demand parameter is designated by customer under a series of prior contracts. So, the demand is considered deterministic. However, the present assumption is applied in cases where the customer demand is uncertain, but the variance of customer demands in the single period is negligible. Fixed costs of facility construction, variable costs of flow between components, transportation, and shortage costs are modeled with uncertainty; this is because these costs are subjected to various conditions that can change, such as sanctions, inflation, natural disasters, etc. To control the emissions of greenhouse gases, an upper bound of emission capacity has been used. This upper bound can have different values due to different environmental conditions. Also, the minimum percentage of the units of product to be disposed and collected from a customer and to be dismantled and shipped from a DC is modeled with uncertainty to handle other uncertainties.

\subsection{Indices of the problem}

Four indexes are defined for factories, warehouses, customers and DCs; four others are also considered for the transportation method between facilities.

\subsection{Parameters}

For greenhouse gases emitted through production, reproduction, maintenance, collection, and transportation, an upper bound of emission capacity was considered with uncertainty. Also, for all parameters with uncertainty, including the fixed cost, variable costs, transportation cost and shortage cost, the upper bound of emission capacity was applied; also, the minimum percentage of the units of product to be disposed and collected from 
TABLE 3. Indices of the mathematical model.

\begin{tabular}{ll}
\hline \hline Indexes & Description \\
\hline$i$ & Index for factories $(i=1,2, \ldots,|I|)$ \\
$j$ & Index for storehouses $(j=1,2, \ldots,|J|)$ \\
$k$ & Index for customers $(k=1,2, \ldots,|K|)$ \\
$l$ & Index for DCs $(l=1,2, \ldots,|L|)$ \\
$m$ & Index for transportation options from factories $(m=1,2, \ldots,|M|)$ \\
$n$ & Index for transportation options from storehouses $(n=1,2, \ldots,|N|)$ \\
$o$ & Index for transportation options from customers $(o=1,2, \ldots,|O|)$ \\
$v$ & Index for transportation options from DCs $(v=1,2, \ldots,|V|)$ \\
\hline
\end{tabular}

a customer and the minimum percentage of the units of product to be dismantled and shipped from a DC were considered as the specified mean and variance, respectively.

\subsection{Decision variables}

The model decision variables were divided into strategic and tactical decision ones. The strategic decision variables included the construction of factories, warehouses and DCs, while the tactical decision variables involved establishing the flows between different facilities and determining the shortage of each customer. Table 5 represents the strategic decision variables and Table 6 illustrates the tactical ones.

\subsection{Model formulation}

In this sub-section, the stochastic cost function and chance constraints are presented. The stochastic objective function involves the cost of strategic and tactical decisions; all of these costs are uncertain. First, a singleobjective stochssastic model is presented, as follows:

$$
\begin{aligned}
\min Q= & \sum_{i=1}^{I} \widetilde{c p_{i}} F p_{i}+\sum_{j=1}^{J} \widetilde{c w_{j}} F w_{j}+\sum_{l=1}^{L} \widetilde{c d_{l}} F d_{l}+\sum_{i=1}^{I} \widetilde{c^{\prime} p_{l}} \sum_{j=1}^{J} \sum_{m=1}^{M} \mathrm{PW}_{i, j}^{m} \\
& +\sum_{j=1}^{J} \widetilde{c^{\prime} h_{j}} \sum_{k=1}^{K} \sum_{n=1}^{N} \mathrm{WC}_{j, k}^{n}+\sum_{k=1}^{K} \widetilde{c^{\prime} c_{k}} \sum_{k=1}^{K} \sum_{n=1}^{N} \mathrm{WC}_{j, k}^{n}+\sum_{l=1}^{L} \widetilde{c^{\prime} d_{l}} \sum_{k=1}^{K} \sum_{o=1}^{O} \mathrm{CI}_{k, l}^{0} \\
& +\sum_{i=1}^{I} \widetilde{c^{\prime} r_{l}} \sum_{l=1}^{L} \sum_{v=1}^{V} \mathrm{IP}_{l, i}^{v}++\sum_{i=1}^{I} \sum_{j=1}^{J} \sum_{m=1}^{M} \widetilde{c^{\prime \prime} p_{l, j}^{m}} \mathrm{PW}_{i, j}^{m}+\sum_{j=1}^{J} \sum_{k=1}^{K} \sum_{n=1}^{N} \widetilde{c^{\prime \prime} w_{j, k}^{n}} \mathrm{WC}_{j, k}^{n} \\
& +\sum_{k=1}^{K} \sum_{l=1}^{L} \sum_{o=1}^{O} \widetilde{c^{\prime \prime} c_{k, l}^{o}} \mathrm{CI}_{k, l}^{0}+\sum_{l=1}^{L} \sum_{i=1}^{I} \sum_{v=1}^{V} \widetilde{c^{\prime \prime} d_{l, i}^{v}} \mathrm{IP}_{l, i}^{v}+\sum_{k=1}^{K} \widetilde{c^{\prime} q_{k}} \mathrm{SH}_{k} .
\end{aligned}
$$

The first, second, and third terms of equation (3.1) are stochastic strategical fixed costs for establishing facilities. The fourth to ninth terms are the random variable costs of production, maintenance, collection, disassembly, and reproduction. The tenth to thirteenth terms are the stochastic transportation costs. The fourteenth term is the random customer's shortage cost.

There are several chance-constraints in the model. As upper bound of emission capacity is assumed uncertain, the constraint of total greenhouse gas emissions can be modeled as the chance constraint shown in equation (3.2).

$$
p\left\{\sum_{i=1}^{I} r p_{i} \sum_{j=1}^{J} \sum_{m=1}^{M} \mathrm{PW}_{i, j}^{m}+\sum_{j=1}^{J} r w_{j} \sum_{k=1}^{K} \sum_{n=1}^{N} \mathrm{WC}_{j, k}^{n}+\sum_{l=1}^{L} r d_{l} \sum_{k=1}^{K} \sum_{o=1}^{O} \mathrm{CI}_{k, l}^{0}\right.
$$


TABLE 4. The defined parameters for modelling.

\begin{tabular}{|c|c|}
\hline Parameter & Explanation \\
\hline$\widetilde{c p_{i}}$ & $\begin{array}{l}\text { Fixed cost (million Rials) for establishing the factory } i \in I \text { with the } \\
\text { mean } \mu c p_{i} \text {, and the variance } \sigma c p_{i}\end{array}$ \\
\hline$\widetilde{c w_{j}}$ & $\begin{array}{l}\text { Fixed cost (million Rials) for establishing the storehouse } j \in J \text { with } \\
\text { the mean } \mu c w_{j} \text {, and the variance } \sigma c w_{j}\end{array}$ \\
\hline$\widetilde{c d}_{l}$ & $\begin{array}{l}\text { Fixed cost (million Rials) for establishing DC } l \in L \text { with the mean } \\
\mu c d_{l} \text {, and the variance } \sigma c d_{l}\end{array}$ \\
\hline$\widetilde{c^{\prime} p_{i}}$ & $\begin{array}{l}\text { Unit variable cost (million Rials) for producing a unit product in the } \\
\text { factory } i \in I \text { with the mean } \mu c^{\prime \prime} \text {, and the variance } \sigma c^{\prime \prime}\end{array}$ \\
\hline$\widetilde{c^{\prime} h_{j}}$ & $\begin{array}{l}\text { Unit variable cost (million Rials) for handling a unit of product in the } \\
\text { storehouse } j \in J \text { with the mean } \mu c^{\prime \prime} \text {, and the variance } \sigma c^{\prime \prime}\end{array}$ \\
\hline$\widetilde{c^{\prime} c_{k}}$ & $\begin{array}{l}\text { Unit variable cost (million Rials) for collecting a unit of product to be } \\
\text { disposed from the customer } k \in K \text { with the mean } \mu c^{\prime \prime} \text {, and the variance } \\
\sigma c^{\prime \prime}\end{array}$ \\
\hline$\overline{c^{\prime} d_{l}}$ & $\begin{array}{l}\text { Unit variable cost (million Rials) for disassembling a unit of product to } \\
\text { be disposed in DC } l \in L \text { with the mean } \mu c^{\prime \prime} \text {, and the variance } \sigma c^{\prime \prime}\end{array}$ \\
\hline$\widetilde{c^{\prime} r_{i}}$ & $\begin{array}{l}\text { Unit variable cost (million Rials) for reproducing a unit product in the } \\
\text { factory } i \in I \text { with the mean } \mu c^{\prime \prime} \text {, and the variance } \sigma c^{\prime \prime}\end{array}$ \\
\hline$\widetilde{c^{\prime} q_{k}}$ & $\begin{array}{l}\text { Unit shortage cost (million Rials) for a unit product in the customer } \\
k \in K \text { with the mean } \mu c^{\prime \prime}, \text { and the variance } \sigma c^{\prime \prime}\end{array}$ \\
\hline$\widehat{c^{\prime \prime} p_{i, j}^{m}}$ & $\begin{array}{l}\text { Unit transportation cost (million Rials) from the factory } i \text { to the store- } \\
\text { house } j \text { with the transportation method } m \text {, the mean } \mu c^{\prime \prime} \text {, and the } \\
\text { variance } \sigma c^{\prime \prime}\end{array}$ \\
\hline$\overline{c^{\prime \prime} w_{j, k}^{n}}$ & $\begin{array}{l}\text { Unit transportation cost (million Rials) from the storehouse } j \text { to the } \\
\text { customer } k \text { with the transportation method } n \text {, the mean } \mu c^{\prime \prime} \text {, and the } \\
\text { variance } \sigma c^{\prime \prime}\end{array}$ \\
\hline $\bar{c}^{\prime \prime} c_{k, l}^{o}$ & $\begin{array}{l}\text { Unit transportation cost (million Rials) for collecting the unit of prod- } \\
\text { uct from the customer } k \text { to DC } l \text { with the transportation method } o \text {, the } \\
\text { mean } \mu c^{\prime \prime} \text {, and the variance } \sigma c^{\prime \prime}\end{array}$ \\
\hline$c^{\prime \prime} d_{l, i}^{v}$ & $\begin{array}{l}\text { Unit transportation cost (million Rials) from DC } l \text { to the factory } i \text { with } \\
\text { the transportation method } v \text {, the mean } \mu c^{\prime \prime} \text {, and the variance } \sigma c^{\prime \prime}\end{array}$ \\
\hline$r p_{i}$ & $\begin{array}{l}\text { Rate of } \mathrm{CO}_{2}(\mathrm{Kg}) \text { released to produce one unit of product in the factory } \\
i\end{array}$ \\
\hline$r w_{j}$ & $\begin{array}{l}\text { Rate of } \mathrm{CO}_{2}(\mathrm{Kg}) \text { released to handle and store one unit of product in } \\
\text { the storehouse } j\end{array}$ \\
\hline$r d_{l}$ & $\begin{array}{l}\text { Rate of } \mathrm{CO}_{2}(\mathrm{Kg}) \text { released to disassemble one unit of product to be } \\
\text { disposed in DC } l\end{array}$ \\
\hline$r r_{i}$ & $\begin{array}{l}\text { Rate of } \mathrm{CO}_{2}(\mathrm{Kg}) \text { released to remanufacture one unit of product to be } \\
\text { dismantled in the factory } i\end{array}$ \\
\hline$r^{\prime \prime} p_{m}$ & $\begin{array}{l}\mathrm{CO}_{2}(\mathrm{Kg}) \text { released by the transportation method } m \text { to forward a unit } \\
\text { of product from factory to storehouse for a unit distance }\end{array}$ \\
\hline$r^{\prime \prime} w_{n}$ & $\begin{array}{l}\mathrm{CO}_{2}(\mathrm{Kg}) \text { released by the transportation method } n \text { to forward a unit } \\
\text { of product from the storehouse to the customer for a unit distance }\end{array}$ \\
\hline$r^{\prime \prime} c_{o}$ & $\begin{array}{l}\mathrm{CO}_{2}(\mathrm{Kg}) \text { released by the transportation method } m \text { to collect a unit } \\
\text { disposal from customer to DC for a unit distance }\end{array}$ \\
\hline$r^{\prime \prime} d_{v}$ & $\begin{array}{l}\mathrm{CO}_{2}(\mathrm{Kg}) \text { released by the transportation method } v \text { to ship a unit of } \\
\text { product to be dismantled from DC to factory for a unit distance }\end{array}$ \\
\hline$u p_{i}$ & Maximum production capacity of the factory $i$ \\
\hline
\end{tabular}


TABLE 4. continued.

\begin{tabular}{|c|c|}
\hline Parameter & Explanation \\
\hline$u w_{j}$ & $\begin{array}{l}\text { Maximum storage and the handling and processing capacity of the } \\
\text { storehouse } j\end{array}$ \\
\hline$u d_{l}$ & Maximum disassembly capacity of DC $l$ \\
\hline$u r$ & Maximum reproduction capacity of the factory $i$ \\
\hline$\alpha p_{i, j}^{m}$ & $\begin{array}{l}\text { Transportation rate from the factory } i \text { to the storehouse } j \text { with the } \\
\text { transportation method } m\end{array}$ \\
\hline$\alpha w_{j, k}^{n}$ & $\begin{array}{l}\text { Transportation rate from the storehouse } j \text { to the customer } k \text { with the } \\
\text { transportation method } n\end{array}$ \\
\hline$\alpha c_{k, l}^{o}$ & $\begin{array}{l}\text { Transportation rate cost for collecting the unit of product from the } \\
\text { customer } k \text { to DC } l \text { with the transportation method } o\end{array}$ \\
\hline$\alpha d_{l, i}^{v}$ & $\begin{array}{l}\text { Transportation rate from DC } l \text { to the factory } i \text { with the transportation } \\
\text { method } v\end{array}$ \\
\hline$s p_{i}$, & Distance $(\mathrm{km})$ between the factory $i$ and the storehouse $j$ \\
\hline$s w_{j, k}$ & Distance $(\mathrm{km})$ between the storehouse $j$ and the customer $k$ \\
\hline$s c_{k, l}$ & Distance $(\mathrm{km})$ between the customer $k$ and $\mathrm{DC} l$ \\
\hline$s d_{l, i}$ & Distance $(\mathrm{km})$ between DC $l$ and the factory $i$ \\
\hline$\tilde{\gamma}$ & $\begin{array}{l}\text { Minimum percentage of the units of product to be disposed to be col- } \\
\text { lected from a customer with the mean } \mu \gamma \text { and the variance } \sigma \gamma\end{array}$ \\
\hline$\tilde{\gamma^{\prime}}$ & $\begin{array}{l}\text { Minimum percentage of the units of product to be dismantled to be } \\
\text { shipped from a DC with the mean } \mu \gamma^{\prime} \text { and the variance } \sigma \gamma^{\prime}\end{array}$ \\
\hline$a_{k}$ & Demand of the customer $k$ \\
\hline$\widetilde{\mathrm{UB}}$ & $\begin{array}{l}\text { Upper bound of the emission capacity of } \mathrm{CO}_{2} \text { released, as determined by } \\
\text { government and regulatory bodies with the mean } \mu \mathrm{UB} \text { and the variance } \\
\sigma \mathrm{UB}\end{array}$ \\
\hline & The chance of rejecting a solution that does not satisfy a constraint \\
\hline$Z_{1}$ & $\begin{array}{l}\text { The lower critical point of the standard normal distribution used for a } \\
(1-\beta) \% \text { chance constraint on the solution obtained }\end{array}$ \\
\hline
\end{tabular}

TABLE 5. Strategic decision variables of the mathematical model.

\begin{tabular}{ll}
\hline \hline Strategic decision variable & Description \\
\hline$F p_{i}$ & $\begin{cases}1 & \text { if the factory } i \text { is established } \\
0 & \text { o.w }\end{cases}$ \\
$F w_{j}$ & $\begin{cases}1 & \text { if the storehouse } j \text { is established } \\
0 & \text { o.w }\end{cases}$ \\
$F d_{l}$ & $\begin{cases}1 & \text { if DC } l \text { is established } \\
0 & \text { o.w }\end{cases}$ \\
\hline
\end{tabular}

$$
\begin{aligned}
& +\sum_{i=1}^{I} r r_{i} \sum_{l=1}^{L} \sum_{v=1}^{V} \mathrm{IP}_{l, i}^{v} \sum_{m=1}^{M} r^{\prime \prime} P_{m} \sum_{i=1}^{I} \sum_{j=1}^{J} \alpha p_{i, j}^{m} s p_{i, j} \mathrm{PW}_{i, j}^{m} \\
& +\sum_{n=1}^{N} r^{\prime \prime} w_{n} \sum_{j=1}^{J} \sum_{k=1}^{K} \alpha w_{j, k}^{n} s w_{j, k} \mathrm{WC}_{j, k}^{n}+\sum_{o=1}^{O} r^{\prime \prime} c_{o} \sum_{k=1}^{K} \sum_{l=1}^{L} \alpha c_{k, l}^{o} s c_{k, l} \mathrm{CI}_{k, l}^{0}
\end{aligned}
$$


TABLE 6. Tactical decision variables of the mathematical model.

\begin{tabular}{ll}
\hline \hline Tactical decision variables & Description \\
\hline $\mathrm{PW}_{i, j}^{m}$ & Amount of the unit product shipped from the factory $i$ to the storehouse \\
& $j$ with the transportation method $m$ \\
$\mathrm{WC}_{j, k}^{n}$ & Amount of the unit product shipped from the storehouse $j$ to the cus- \\
$\mathrm{CI}_{k, l}^{0}$ & tomer $k$ with the transportation method $n$ \\
$\mathrm{IP}_{l, i}^{v}$ & Amount of the unit product to be disposed and collected from the \\
$\mathrm{SH}_{k}$ & customer $k$ to DC $l$ with the transportation method $o$ \\
\hline
\end{tabular}

$$
\left.+\sum_{v=1}^{V} r^{\prime \prime} d_{p} \sum_{j=1}^{J} \sum_{k=1}^{K} \alpha d_{l, i}^{v} s d_{l, i} \mathrm{IP}_{l, i}^{v} \leq \widetilde{\mathrm{UB}}\right\} \geq 1-\beta .
$$

Similarly, since the parameters of the minimum percentage of the units of product to be disposed to be collected from a customer and the minimum percentage of the units of product to be dismantled to be shipped from a DC are considered as stochastic parameters, the constraints for establishing the return flow from customer to DCs and DCs to factories can also be modeled as chance-constraints, as shown in equations (3.3) and (3.4).

$$
\begin{array}{cl}
p\left\{\sum_{l=1}^{I} \sum_{o=1}^{O} \mathrm{CI}_{k, l}^{0} \geq \widetilde{\gamma} \cdot\left(d_{k}-\mathrm{SH}_{k}\right)\right\} \geq 1-\beta & \forall k \in K \\
p\left\{\sum_{i=1}^{I} \sum_{v=1}^{V} \mathrm{IP}_{l, i}^{v} \geq \widetilde{\gamma^{\prime}} \cdot \sum_{k=1}^{K} \mathrm{CI}_{k, l}^{0}\right\} \geq 1-\beta & \forall l \in L .
\end{array}
$$

\subsection{Model reformulation}

The process of converting a stochastic single-objective model to a deterministic bi-objective one is described here. First, the objective function and then the chance constraints are completely rewritten.

The random function $Q$, as shown in equation (3.1), consists of the mean $F_{1}$ and the variance $F_{2}$. The mean and variance of $Q$ must be calculated and minimized separately to handle uncertainty. As a result, the single-objective function should be converted into $F_{1}$ and $F_{2}$ functions.

$$
\begin{aligned}
& F 1=E(Q) \\
& F 2=\operatorname{Var}(Q) .
\end{aligned}
$$

Each of the chance constraints should be transformed into the deterministic mode. For example, in equation (3.2), given the assumption of the normal distribution for the upper bound of the emission capacity, $\frac{\widetilde{\mathrm{UB}}-\mu \mathrm{UB}}{\sqrt{\sigma \mathrm{UB}}}$ has the standard normal distribution with the mean 0 and the variance 1. According to equation (3.6), the function of the total emission is equal to $h$. In this way, the cumulative distribution function is shown as equation (3.7):

$$
\begin{aligned}
h= & \sum_{i=1}^{I} r p_{i} \sum_{j=1}^{J} \sum_{m=1}^{M} \mathrm{PW}_{i, j}^{m}+\sum_{j=1}^{J} r w_{j} \sum_{k=1}^{K} \sum_{n=1}^{N} \mathrm{WC}_{j, k}^{n}+\sum_{l=1}^{L} r d_{l} \sum_{k=1}^{K} \sum_{o=1}^{O} \mathrm{CI}_{k, l}^{0} \\
& +\sum_{i=1}^{I} r r_{i} \sum_{l=1}^{L} \sum_{v=1}^{V} \mathrm{IP}_{l, i}^{v}+\sum_{m=1}^{M} r^{\prime \prime} P_{m} \sum_{i=1}^{I} \sum_{j=1}^{J} \alpha p_{i, j}^{m} s p_{i, j} \mathrm{PW}_{i, j}^{m}
\end{aligned}
$$




$$
\begin{aligned}
& +\sum_{n=1}^{N} r^{\prime \prime} w_{n} \sum_{j=1}^{J} \sum_{k=1}^{K} \alpha w_{j, k}^{n} s w_{j, k} \mathrm{WC}_{j, k}^{n}+\sum_{o=1}^{O} r^{\prime \prime} c_{o} \sum_{k=1}^{K} \sum_{l=1}^{L} \alpha c_{k, l}^{0} s c_{k, l} \mathrm{CI}_{k, l}^{0} \\
& +\sum_{v=1}^{V} r^{\prime \prime} d_{p} \sum_{j=1}^{J} \sum_{k=1}^{K} \alpha d_{l, i}^{v} s d_{l, i} \mathrm{IP}_{l, i}^{v} \\
p(\widetilde{\mathrm{UB}} \geq h)= & F\left(-\frac{h-\mu \mathrm{UB}}{\sqrt{\sigma^{2} \mathrm{UB}}}\right) .
\end{aligned}
$$

According to the table values of the standard normal distribution function and the coefficient confidence value, Eq. (3.7) is rewritten as Eq. (3.8).

$$
-\frac{h-\mu \mathrm{UB}}{\sqrt{\sigma \mathrm{UB}}} \geq Z_{1-\beta} .
$$

After simplifying equation (3.8), equation (3.11) is obtained.

After covering uncertainty in these parameters, the deterministic non-linear bi-objective model is as follows:

$$
\begin{aligned}
\min F_{1}= & \sum_{i=1}^{I} \mu c p_{i} F p_{i}+\sum_{j=1}^{J} \mu c w_{j} F w_{j}+\sum_{l=1}^{L} \mu c d_{l} F d_{l}+\sum_{i=1}^{I} \mu c^{\prime} p_{i} \sum_{j=1}^{J} \sum_{m=1}^{M} \mathrm{PW}_{i, j}^{m} \\
& +\sum_{j=1}^{J} \mu c^{\prime} h_{j} \sum_{k=1}^{K} \sum_{n=1}^{N} \mathrm{WC}_{j, k}^{n}+\sum_{k=1}^{K} \mu c^{\prime} c_{k} \sum_{k=1}^{K} \sum_{n=1}^{N} \mathrm{WC}_{j, k}^{n}++\sum_{l=1}^{L} \mu c^{\prime} d_{l} \sum_{k=1}^{K} \sum_{o=1}^{O} \mathrm{CI}_{k, l}^{0} \\
& +\sum_{i=1}^{I} \mu c^{\prime} r_{i} \sum_{l=1}^{L} \sum_{v=1}^{V} \mathrm{IP}_{l, i}^{v}+\sum_{i=1}^{I} \sum_{j=1}^{J} \sum_{m=1}^{M} \mu c^{\prime \prime} p_{i, j}^{m} \mathrm{PW}_{i, j}^{m}+\sum_{j=1}^{J} \sum_{k=1}^{K} \sum_{n=1}^{N} \mu c^{\prime \prime} w_{j, k}^{n} \mathrm{WC}_{j, k}^{n} \\
& +\sum_{k=1}^{K} \sum_{l=1}^{L} \sum_{o=1}^{O} \mu c^{\prime \prime} c_{k, l}^{0} \mathrm{CI}_{k, l}^{0}+\sum_{l=1}^{L} \sum_{i=1}^{I} \sum_{v=1}^{V} \mu c^{\prime \prime} d_{l, i}^{v} \mathrm{IP}_{l, i}^{v}+\sum_{k=1}^{K} \mu c^{\prime} q_{k} \mathrm{SH}_{k} \\
\min F_{2}= & \sum_{i=1}^{I} \sigma c p_{i} F p_{i}^{2}+\sum_{j=1}^{J} \sigma c w_{j} F w_{j}^{2}+\sum_{l=1}^{L} \sigma c d_{l} F d_{l}^{2}+\sum_{i=1}^{I} \sigma c^{\prime} p_{i} \sum_{j=1}^{J} \sum_{m=1}^{M} \mathrm{PW}_{i, j}^{m^{2}} \\
& +\sum_{j=1}^{J} \sigma c^{\prime} h_{j} \sum_{k=1}^{K} \sum_{n=1}^{N} \mathrm{WC}_{j, k}^{n^{2}}+\sum_{k=1}^{K} \sigma c^{\prime} c_{k} \sum_{k=1}^{K} \sum_{n=1}^{N} \mathrm{WC}_{j, k}^{n^{2}}++\sum_{l=1}^{L} \sigma c^{\prime} d_{l} \sum_{k=1}^{K} \sum_{o=1}^{O} \mathrm{CI}_{k, l}^{0^{2}} \\
& +\sum_{i=1}^{I} \sigma c^{\prime} r_{i} \sum_{l=1}^{L} \sum_{v=1}^{V} \mathrm{IP}_{l, i}^{v^{2}}+\sum_{i=1}^{I} \sum_{j=1}^{J} \sum_{m=1}^{M} \sigma c^{\prime \prime} p_{i, j}^{m} \mathrm{PW}_{i, j}^{m^{2}}+\sum_{j=1}^{J} \sum_{k=1}^{K} \sum_{n=1}^{N} \sigma c^{\prime \prime} w_{j, k}^{n} \mathrm{WC}_{j, k}^{n^{2}} \\
& +\sum_{k=1}^{K} \sum_{l=1}^{L} \sum_{o=1}^{O} \sigma c^{\prime \prime} c_{k, l}^{0} \mathrm{CI}_{k, l}^{0^{2}}++\sum_{l=1}^{L} \sum_{i=1}^{I} \sum_{v=1}^{V} \sigma c^{\prime \prime} d_{l, i}^{v} \mathrm{IP}_{l, i}^{v^{2}}+\sum_{k=1}^{K} \sigma c^{\prime} q_{k} \mathrm{SH}_{k}^{2} .
\end{aligned}
$$

Equations (3.9) and (3.10) are the first and second objective functions of the deterministic form of the model. Equation (3.9) refers to the expected value of a stochastic strategic and tactical cost function. The first, second, and third terms are the fixed costs of establishing factories, warehouses, and customers. The fourth to ninth terms are the variable costs of production, maintenance, collection, disassembly, and reproduction. The tenth to thirteenth terms are the transportation costs between factories to warehouses, warehouses to customers, customers to DCs, and DCs to factories. The cost of the transportation system depends on the chosen transportation mode in the network. The fourteenth term is the penalty cost for the customer's shortage. Penalty cost of the customer shortage includes the cost of losing the customer or the cost of delay in receiving the 
product price. Equation (3.10) describes the variance of equation (3.1), which controls the scatter of uncertain costs. The first, second, and third terms are the variance of the fixed costs of establishing factories, warehouses, and customers. The fourth to ninth terms are the variance of the variable costs of production, maintenance, collection, disassembly, and reproduction. The tenth to thirteenth terms are the variance of the transportation costs between factories to warehouses, warehouses to customers, customers to DCs, and DCs to factories. The fourteenth term is the variance of the penalty cost for the customer's shortage. This equation is the mixed integer nonlinear programming (MINLP) form.

Subject to:

$$
\begin{aligned}
\sum_{i=1}^{I} r & p_{i} \sum_{j=1}^{J} \sum_{m=1}^{M} \mathrm{PW}_{i, j}^{m}+\sum_{j=1}^{J} r w_{j} \sum_{k=1}^{K} \sum_{n=1}^{N} \mathrm{WC}_{j, k}^{n}+\sum_{l=1}^{L} r d_{l} \sum_{k=1}^{K} \sum_{o=1}^{O} \mathrm{CI}_{k, l}^{0} \\
& +\sum_{i=1}^{I} r r_{i} \sum_{l=1}^{L} \sum_{v=1}^{V} \mathrm{IP}_{l, i}^{v} \sum_{m=1}^{M} r^{\prime \prime} p_{m}+\sum_{i=1}^{I} \sum_{j=1}^{J} \alpha p_{i, j}^{m} s p_{i, j} \mathrm{PW}_{i, j}^{m} \\
& +\sum_{n=1}^{N} r^{\prime \prime} w_{n}+\sum_{j=1}^{J} \sum_{k=1}^{K} \alpha w_{j, k}^{n} s w_{j, k} \mathrm{WC}_{j, k}^{n}+\sum_{o=1}^{O} r^{\prime \prime} c_{o}+\sum_{k=1}^{K} \sum_{l=1}^{L} \alpha c_{k, l}^{o} s c_{k, l} \mathrm{CI}_{k, l}^{0} \\
& +\sum_{v=1}^{V} r^{\prime \prime} d_{p} \sum_{j=1}^{J} \sum_{k=1}^{K} \alpha d_{l, i}^{v} s d_{l, i} \mathrm{IP}_{l, i}^{v}+Z_{1-\beta} \sqrt{\sigma \mathrm{UB}} \leq \mu \mathrm{UB}
\end{aligned}
$$

$\sum_{j=1}^{J} \sum_{m=1}^{M} \mathrm{PW}_{i, j}^{m} \leq u p_{i} F p_{i}$

$\forall i \in I$

$\sum_{l=1}^{L} \sum_{v=1}^{V} \mathrm{IP}_{l, i}^{v} \leq u r_{i} F p_{i}$

$\forall i \in I$

$\sum_{i=1}^{I} \sum_{m=1}^{M} \mathrm{PW}_{i, j}^{m} \leq u w_{j} F w_{j}$

$\forall j \in J$

$\sum_{k=1}^{K} \sum_{o=1}^{O} \mathrm{CI}_{k, l}^{0} \leq u d_{l} F d_{l}$

$\forall l \in L$

$\sum_{i=1}^{I} \sum_{m=1}^{M} \mathrm{PW}_{i, j}^{m} \geq \sum_{k=1}^{K} \sum_{n=1}^{N} \mathrm{WC}_{j, k}^{n}$

$\forall j \in J$

$\sum_{j=1}^{J} \sum_{n=1}^{N} \mathrm{WC}_{j, k}^{n} \geq d_{k}-\mathrm{SH}_{k}$

$\forall k \in K$

$\sum_{l=1}^{L} \sum_{o=1}^{O} \mathrm{CI}_{k, l}^{0} \leq d_{k}-\mathrm{SH}_{k}$

$\forall k \in K$

$\sum_{l=1}^{I} \sum_{o=1}^{O} \mathrm{CI}_{k, l}^{0}+\mu \gamma \mathrm{SH}_{k}+Z_{1-\beta} \sqrt{\sigma \gamma \mathrm{SH}_{k}^{2}+\sigma \gamma d_{k}^{2}} \geq \mu \gamma d_{k} \quad \forall k \in K$

$\sum_{i=1}^{I} \sum_{v=1}^{V} \mathrm{IP}_{l, i}^{v}+Z_{1-\beta} \sqrt{\sigma \gamma^{\prime} \sum_{k=1}^{K} \mathrm{CI}_{k, l}^{0^{2}}} \geq \mu \gamma^{\prime} \cdot \sum_{k=1}^{K} \mathrm{CI}_{k, l}^{0} \quad \forall l \in L$

$F p_{i}, F w_{j}, F d_{l} \in\{0,1\}$ 


$$
\mathrm{PW}_{i, j}^{m} \geq 0, \mathrm{WC}_{j, k}^{n} \geq 0, \mathrm{CI}_{k, l}^{0} \geq 0, \mathrm{IP}_{l, i}^{v} \geq 0, \mathrm{SH}_{k} \geq 0 .
$$

Equation (3.11) is the deterministic form of equation (3.2), indicating the total amount of $\mathrm{CO}_{2}$ released. The first to fourth terms refer to $\mathrm{CO}_{2}$ emission through producing, holding, disassembling, and remanufacturing. The fifth to eighth terms describe the $\mathrm{CO}_{2}$ released through transportation between factories to warehouses, warehouses to customers, customers to DCs, and DCs to factories. The emission of the transportation system depends on the chosen transportation mode in the network. The total amount of greenhouse emission should be lower than the upper bound of the emission capacity. The upper bound of $\mathrm{CO}_{2}$ released is assumed as a stochastic parameter, as determined by government or regulatory bodies. Equations (3.12)-(3.15) show that the total inputs to each of the facilities should not exceed their capacities. These Equations are called facility capacity constraints. Equations (3.12) and (3.13) refer to the maximum capacity of production and re-production in the factories. The total amount of the units produced and reproduced in each active factory to be sent to different storehouses must be less than its maximum production and reproduction capacity. Equation (3.14) is related to the maximum capacity for the control and storage in storehouses. The total amount of the units sent from different factories to each storehouses should not exceed its maximum capacity. Equation (3.15) also refers to the maximum capacity of a disassembly in DCs. If a DC is built, the total amount of the units disassembled must be less than its maximum disassembly capacity. Equation (3.16) states that the amount of the output products from storehouses should be equal or smaller than that of the input products entering them. These constraints balance the flow of materials in storehouse. Equation (3.17) shows that all products shipped from storehouses to each customer should be as many as customer demands. The difference between the demand and product received by the customer has been considered a shortage. In fact, each customer's demand may be faced with shortage. Equation (3.18) determines that the amount of products to be disposed from each customer is not greater than that received by them. Each customer can send as much as the amount of the products received by DC units as the waste products. The total received products to each customer node is equal to the difference between the demand and shortage of customers. Equations (3.19) and (3.20) are the definite forms of equations (3.3) and (3.4). These constraints force the model to establish the return flow in the supply chain. According to equation (3.19), a minimum percentage of the received products by each customer should be considered as waste products. Equation (3.20) also forces the model to return a minimum percentage of the disposable products for reproduction to factories. The minimum percentage of the units of product to be disposed to be collected from a customer and dismantled to be shipped from a DC is deemed uncertain based on the experience of industry owners. Equation (3.21) demonstrates the binary variables of the strategic decisions (locating facilities and determining the transportation mode between them); equation (3.22) represents the continuous variables of tactical decisions (allocating the flow between facilities).

\section{Proposed solution methods}

To solve multi-objective programming models, there are many methods, depending on the time and type of information obtained from decision maker. Multi-objective decision-making (MODM) methods, based on the interaction between decision maker and analyst, are divided into four categories. The first category belongs to the methods that make decision without information from decision-maker. The global criteria, Max-Min, and filtering/displaced ideal solution (DIS) are related to this category. The second category refers to the methods that act on the basis of the primitive information from decision-maker. The utility function and the $\varepsilon$-constraint method in this category can apply only quantitative information. Goal programming, goal attainment, and lexicography are methods belonging to this category; they use both quantitative and qualitative information for decision making. The third category includes the methods that operate with the interactive information from decision maker. Many methods, such as the Geofrion method, SIMOLP method, STEM method, etc., can be fitted into this category. The fourth category consists of those methods that take the initial information from decision maker after the problem is solved; these are such as multi-criteria simplex method, the minimum deviation method, the Denovo programming and so on $[9,26]$. 
In this work, four MODM methods including $\varepsilon$-constraint, goal-programming, goal-attainment, and lexicography methods were used from the first and second categories. The efficiency of the solutions of these methods was compared with that of Pareto-based and optimality-based analyses. For the Pareto-based analysis, the expected value and variance of the costs were compared using the $\varepsilon$-constraint method at different levels. For the optimality-based analysis, goal programming, goal attainment, and lexicography methods were compared using two groups of analyses: statistical approaches (hypothesis testing) and multi-criteria decision-making (MCDM). In both analyses, the solutions of different methods in terms of CPU time and quality were investigated.

All analyses were performed to improve decision-making and to optimize the supply chain structure. Different MODM methods use different processes to solve the model. The $\varepsilon$-constraint method considers one or more main objectives and also meets a minimum level of other less important objectives. The goal programming brings each objective to its goal. The goal attainment minimizes the maximum distance of the objectives from their goals, and the lexicography method minimizes the distance of $e$ objectives from their optimal value. A summary of the MODM methods used to solve the model is as follows:

\section{1. $\varepsilon$-constraint method}

In this method, one of the objectives is considered as the main objective function, and the upper and lower bounds are assumed for the others in proportion to the acceptable risk level.

The following model represents this method. obj is the main objective and $Q_{j}$ refers to $m-1$ less important objectives.

$$
\begin{aligned}
& \min \text { obj } \\
& \text { s.t. } \\
& \begin{array}{l}
L_{j} \leq Q_{j} \leq U_{j} \\
Q_{j} \in S .
\end{array}
\end{aligned}
$$

For all methods, $S$ is the feasible region of the original model. In this research, after selecting each of the objectives as the main objective, the relevant efficient solutions were generated to form the Pareto-front.

\subsection{Goal programming}

According to this method, a numerical value called goal is considered for each of the objectives. For each objective, depending on the type of the objective function (cost or profit), there is a desirable deviation and an undesirable one from the goal. The diversion of the objectives from their goals is determined by $d_{j}^{+}, d_{j}^{-}$. The amount of the undesirable deviations of the objectives from goals is considered as the new objective function and the original objective function is placed in the constraints. The following model describes this method:

$$
\begin{array}{ll}
\min \sum_{j=1}^{m} w_{j} X_{j}\left(d_{j}^{+}, d_{j}^{-}\right) & \\
\text {s.t. } & \forall j=1, \ldots, m \\
Q_{j}-d_{j}^{+}+d_{j}^{-}=Q_{j}^{*} & \\
d_{j}^{+} \geq 0, d_{j}^{-} \geq 0 & \\
Q_{j} \in S . &
\end{array}
$$

In this model, $w_{j}$ is the weight given by the decision maker according to the priority of the objectives, often in terms of the power of 10 , and $Q_{j}^{*}$ refers to the goals. Also, the function $X_{j}\left(d_{j}^{+}, d_{j}^{-}\right)$is defined as follows:

$$
X_{j}\left(d_{j}^{+}, d_{j}^{-}\right)= \begin{cases}d_{j}^{+} & \text {if } Q_{j} \text { is a cost function } \\ d_{j}^{-} & \text {if } Q_{j} \text { is a prof function } \\ d_{j}^{+}+d_{j}^{-} & \text {o.w. }\end{cases}
$$


The Goal programming method for the presented bi-objective mathematical model is developed as follows:

$$
\begin{aligned}
& \min d_{1}^{+}+d_{2}^{+} \\
& \text {s.t. } \\
& F_{1}-d_{1}^{+}+d_{1}^{-}=F_{1}^{*} \\
& F_{2}-d_{2}^{+}+d_{2}^{-}=F_{2}^{*} \\
& d_{1}^{+}, d_{2}^{+} \geq 0, d_{1}^{-}, d_{2}^{-} \geq 0 \\
& F_{1}, F_{2} \in S .
\end{aligned}
$$

It should be noted that $F_{1}^{*}$ and $F_{2}^{*}$ are the optimal values of the first and second objective functions solved by the individual optimization method.

\subsection{Goal attainment}

Goal attainment is an extended form of goal programming. In this method, the maximum diversion of objectives from their goals is minimized using the developed model, as shown below:

$$
\begin{aligned}
& \min y \\
& \text { s.t. } \\
& Q_{j}+w_{j}^{\prime} y \geq Q_{j}^{*} \\
& y \text { is un-restricted in sign, } \\
& Q_{j} \in S .
\end{aligned}
$$

The value of $w_{j}^{\prime}$ refers to the weights that have an inverse relationship with the priority of the objectives. Also, $\sum_{j=1}^{m} w_{j}^{\prime}=1$. In this study, the priority of the goals was assumed to be equal. The Goal attainment method for the presented bi-objective model is described as follows:

$$
\begin{aligned}
& \min y \\
& \text { s.t. } \\
& F_{1}+\frac{1}{2} y \geq F_{1}^{*} \\
& F_{2}+\frac{1}{2} y \geq F_{2}^{*} \\
& y \text { is urs } \\
& F_{1}, F_{2} \in S .
\end{aligned}
$$

\subsection{Global criteria}

This method is such that at first, the optimal value of all objectives is calculated separately. Then, the distance of each of the targets from their optimal amount is minimized using the following function:

$$
\begin{aligned}
& \min \left(\left(\frac{Q_{j}-Q_{j}^{*}}{Q_{j}^{*}}\right)^{p}\right)^{\frac{1}{p}} \\
& \text { s.t. } \\
& Q_{j} \in S .
\end{aligned}
$$

The value of $p$ is determined based on the importance of the goal distance from its optimal value. In this research, the Global criteria method for the presented bi-objective mathematical model is provided as follows:

$$
\min \frac{F_{1}-F_{1}^{*}}{F_{1}^{*}}+\frac{F_{2}-F_{2}^{*}}{F_{2}^{*}}
$$


TABle 7. Effective solution set of the Pareto front.

\begin{tabular}{lll}
\hline \hline Number of effective solutions & $\begin{array}{l}\text { Excepted value of cost } \\
\text { (million Rials) }\end{array}$ & $\begin{array}{l}\text { Standard deviation of cost } \\
\text { (million Rials) }\end{array}$ \\
\hline s1 & 23969.953 & 504.907 \\
s2 & 23982.676 & 475.38 \\
s3 & 24017.858 & 445.853 \\
s4 & 24085.915 & 416.327 \\
s5 & 24204.675 & 386.8 \\
s6 & 24418.075 & 357.273 \\
s7 & 24713.637 & 327.747 \\
s8 & 25031.97 & 298.22 \\
s9 & 25494.778 & 268.693 \\
s10 & 26112.31 & 239.167 \\
s11 & 27888.986 & 209.64 \\
\hline
\end{tabular}

s.t.

$F_{1}, F_{2} \in S$.

\section{EXPERIMENTAL EXAMPLES AND SENSITIVE ANALYSIS}

In this section, numerical experiments and various analyses were conducted to help decision makers design a structure of green supply chain. Initially, 30 different examples with the same size, including 3 factories, 3 storehouses, 8 customers, 3 DCs and 3 different transportation options between facilities, were used to compare different objective functions and solution methods using the GAMS software. Two groups of analyses were conducted on the existing data to compare the solutions and facilitate the decision-making process. A brief explanation of these analyses is presented below. The decision maker can use the Pareto-based approach to generate a preferred solution. The decision maker can also apply the optimality-based approach to choose the best MODM method based on three effective criteria and solve the resulting single objective model in the best way.

\subsection{Pareto-based analysis}

In multi-objective models, objectives are usually contradictory. This makes it impossible to find a solution in which all objectives would be optimized. Decision makers are usually looking for an effective solution, rather than finding the optimal one for all objectives. The Pareto front approach provides a set of effective solutions to the problem. In this study, the Pareto front approach is described in Table 7. The first row of the table is the optimal point of the first objective function, while the last one represents the optimal point of the second objective function. Between these two points, 9 preferable solutions are presented for the model. Figure 2 shows these effective solutions and the comparison between them.

The Pareto-based analysis was performed using the $\varepsilon$-constraint method. On the Pareto front, the confidence level was 0.95 for the chance constraints. The decision maker, in accordance with Figure 2 and in proportion to the level of the risk acceptance in each of the objective functions, could select any of the efficient solutions and implement the design process based on them. If the decision maker assumes the same priority for goals, the analyst selects the ninth effective response from the Pareto front approach.

\subsection{Optimality-based analysis}

Optimality-based analyses are based on three MODM methods. At first, 30 different examples considering the differences in some effective parameters were solved using goal programming, goal attainment, and global 


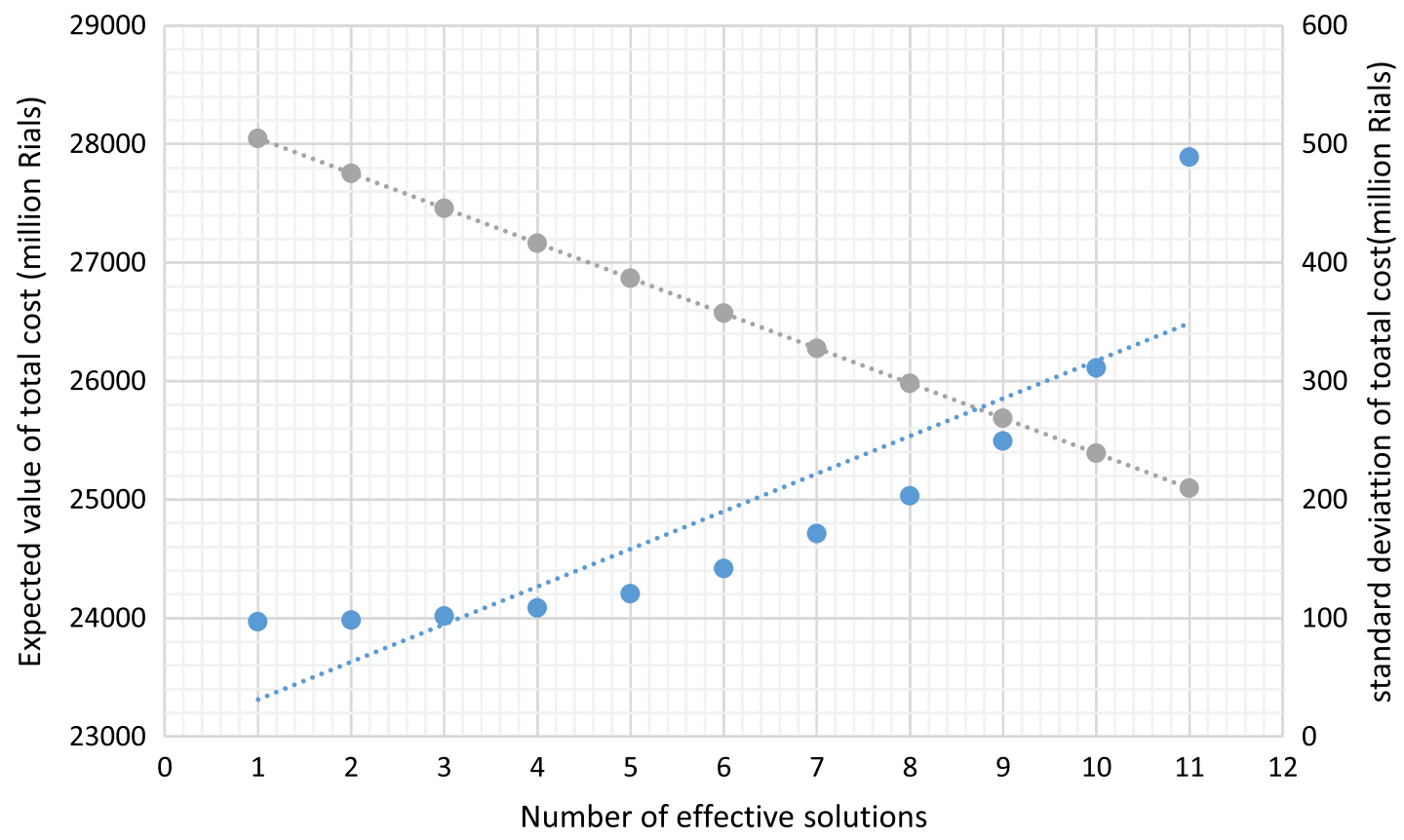

Figure 2. Pareto optimal set.

TABLE 8. Comparison of the three MODM methods in terms of the expected value of the total cost, variance of costs, and CPU time based on 30 test problems created by changes in effective uncertain parameters.

\begin{tabular}{|c|c|c|c|c|c|c|c|c|c|c|}
\hline \multirow{2}{*}{$\begin{array}{l}\text { Test } \\
\text { No. }\end{array}$} & \multirow{2}{*}{$\begin{array}{l}\text { Changed } \\
\text { Parameters }\end{array}$} & \multicolumn{3}{|c|}{ Global criteria } & \multicolumn{3}{|c|}{ Goal attainment } & \multicolumn{3}{|c|}{ Goal programming } \\
\hline & & $\begin{array}{l}\begin{array}{l}\text { First } \\
\text { objective } \\
\text { (million } \\
\text { Rials) }\end{array} \\
\end{array}$ & $\begin{array}{l}\begin{array}{l}\text { Second } \\
\text { objective } \\
\text { (million } \\
\text { Rials) }\end{array} \\
\end{array}$ & $\begin{array}{l}\text { CPU time } \\
\text { (second) }\end{array}$ & $\begin{array}{l}\text { First } \\
\text { objective } \\
\text { (million } \\
\text { Rials) } \\
\end{array}$ & $\begin{array}{l}\text { Second } \\
\text { objective } \\
\text { (million } \\
\text { Rials) }^{2}\end{array}$ & $\begin{array}{l}\text { CPU } \\
\text { time } \\
\text { (second) }\end{array}$ & $\begin{array}{l}\text { First } \\
\text { objective } \\
\text { (million } \\
\text { Rials) } \\
\end{array}$ & $\begin{array}{l}\begin{array}{l}\text { Second } \\
\text { objective } \\
\text { (million } \\
\text { Rials) }\end{array} \\
\end{array}$ & $\begin{array}{l}\text { CPU } \\
\text { time } \\
\text { (second) }\end{array}$ \\
\hline 1 & $d_{1}=16$ & 26963.905 & 40931.363 & 20.39 & 23366.499 & 230366.499 & 3.09 & 23361.144 & 244559.902 & 6.02 \\
\hline 2 & $d_{4}=18$ & 27116.527 & 41808.399 & 30.47 & 23477.387 & 230477.387 & 10.65 & 23472.017 & 243975.52 & 11.89 \\
\hline 3 & $d_{1}=18$ & 27303.256 & 42511.615 & 11.45 & 23672.984 & 230672.984 & 3.34 & 23499.63 & 245717.371 & 7.28 \\
\hline 4 & $\begin{array}{l}d_{5}=14 \\
\mu c a p=200\end{array}$ & 27241.518 & 48007.299 & 15.66 & 23765.971 & 230765.971 & 7.51 & 23586.226 & 259770.284 & 3.9 \\
\hline 5 & $d_{3}=14$ & 27471.786 & 43407.956 & 11 & 23821.817 & 230821.817 & 4.7 & 23647.088 & 248448.626 & 4.99 \\
\hline 6 & $\begin{array}{l}\mu c a p=250 \\
\text { Beta }=1.95\end{array}$ & 27481.302 & 40286.043 & 48.54 & 23730.39 & 230730.39 & 3.34 & 23715.228 & 267604.42 & 25.74 \\
\hline 7 & $d_{8}=16$ & 27413.126 & 49031.757 & 184.53 & 23926.676 & 230926.676 & 3.43 & 23742.791 & 264909.379 & 16.32 \\
\hline 8 & $\begin{array}{l}d_{2}=24 \\
\text { нсар }=200\end{array}$ & 27243.76 & 48099.096 & 359.51 & 23764.739 & 230764.213 & 4.87 & 23753.538 & 263986.863 & 4.19 \\
\hline 9 & $\begin{array}{l}d_{4}=20 \\
\mu \text { сар }=200\end{array}$ & 27406.266 & 48943.766 & 8.29 & 23910.201 & 230910.2 & 4.15 & 23897.534 & 266419.295 & 7.96 \\
\hline 10 & $\begin{array}{l}\mu c a p=210 \\
\text { Beta }=1.95\end{array}$ & 27360.713 & 50084.786 & 205.69 & 23907.739 & 230907.739 & 2.53 & 23907.703 & 231818.551 & 9.13 \\
\hline 11 & $\begin{array}{l}d_{2}=24 \\
\text { нсар }=180\end{array}$ & 27141.249 & 56146.37 & 24.85 & 23928.253 & 230928.253 & 1.82 & 23927.628 & 232897.121 & 4.04 \\
\hline 12 & $\begin{array}{l}\text { Original } \\
\text { problem }\end{array}$ & 27644.38 & 44174.361 & 10.46 & 23979.884 & 230979.884 & 3.01 & 23969.953 & 254930.985 & 7.1 \\
\hline
\end{tabular}


TABLE 8. continued.

\begin{tabular}{|c|c|c|c|c|c|c|c|c|c|c|}
\hline \multirow{2}{*}{$\begin{array}{l}\text { Test } \\
\text { No. }\end{array}$} & \multirow{2}{*}{$\begin{array}{l}\text { Changed } \\
\text { Parameters }\end{array}$} & \multicolumn{3}{|c|}{ Global criteria } & \multicolumn{3}{|c|}{ Goal attainment } & \multicolumn{3}{|c|}{ Goal programming } \\
\hline & & $\begin{array}{l}\text { First } \\
\text { objective } \\
\text { (million } \\
\text { Rials) }\end{array}$ & $\begin{array}{l}\text { Second } \\
\text { objective } \\
\text { (million } \\
\text { Rials) }\end{array}$ & $\begin{array}{l}\text { CPU time } \\
\text { (second) }\end{array}$ & $\begin{array}{l}\text { First } \\
\text { objective } \\
\text { (million } \\
\text { Rials) }\end{array}$ & $\begin{array}{l}\text { Second } \\
\text { objective } \\
\text { (million } \\
\text { Rials) }{ }^{2}\end{array}$ & $\begin{array}{l}\mathrm{CPU} \\
\text { time } \\
\text { (second) }\end{array}$ & $\begin{array}{l}\text { First } \\
\text { objective } \\
\text { (million } \\
\text { Rials) }\end{array}$ & 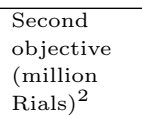 & $\begin{array}{l}\text { CPU } \\
\text { time } \\
\text { (second) }\end{array}$ \\
\hline 13 & $\begin{array}{l}d_{4}=20 \\
\mu \text { cap }=190, \\
\text { Beta }=1.95\end{array}$ & 27083.966 & 57503.114 & 9.2 & 23988.401 & 217538.55 & 5.01 & 23988.401 & 217033.095 & 8.41 \\
\hline 14 & $d_{8}=18$ & 27750.988 & 50773.741 & 12.69 & 24238.743 & 231238.723 & 8.18 & 24052.81 & 267287.822 & 4.67 \\
\hline 15 & $\begin{array}{l}d_{5}=14, \\
d_{8}=20, \\
\mu \text { cap }=210, \\
\text { Beta }=1.95\end{array}$ & 27526.67 & 50854.123 & 8.52 & 24059.596 & 225321.42 & 3.2 & 24059.595 & 225320.918 & 5.91 \\
\hline 16 & $\begin{array}{l}d_{2}=24 \\
\mu \text { cap }=17\end{array}$ & 27075.816 & 61417.36 & 96.78 & 24108.506 & 210717.214 & 3.68 & 24108.505 & 210713.308 & 6.56 \\
\hline 17 & $d_{8}=19$ & 27919.09 & 51680.835 & 231.73 & 24394.805 & 231394.805 & 6.67 & 24209.328 & 266530.064 & 4.11 \\
\hline 18 & $\mu c a p=180$ & 27477.764 & 58253.36 & 8.34 & 24249.956 & 231249.95 & 4.21 & 24247.015 & 237897.483 & 4.08 \\
\hline 19 & $\begin{array}{l}d_{3}=16 \\
d_{8}=16 \\
\mu \text { cap }=180\end{array}$ & 27648.387 & 59367.685 & 9.76 & 24432.453 & 231432.453 & 4.01 & 24256.059 & 235968.858 & 7.07 \\
\hline 20 & $\begin{array}{l}d_{5}=14, \\
d_{8}=20, \\
\mu \text { cap }=190, \\
\text { Beta }=1.95\end{array}$ & 27422.109 & 59546.645 & 9.81 & 24319.618 & 219163.638 & 4.43 & 24319.618 & 219161.962 & 30.02 \\
\hline 21 & $d_{8}=20$ & 28086.231 & 52612.781 & 6.85 & 24550.872 & 231550.872 & 3.65 & 24365.761 & 265897.882 & 5.1 \\
\hline 22 & $\mu c a p=170$ & 27410.765 & 63704.858 & 75.75 & 24427.485 & 215754.291 & 4.51 & 24427.485 & 215754.175 & 14.51 \\
\hline 23 & $\begin{array}{l}d_{2}=24 \\
d_{5}=18 \\
d_{6}=19 \\
d_{8}=20 \\
\mu \text { cap }=280\end{array}$ & 28422.34 & 38450.485 & 30.05 & 24463.724 & 231463.719 & 15.26 & 24448.75 & 300949.648 & 23.53 \\
\hline 24 & $\begin{array}{l}d_{3}=16 \\
d_{8}=18 \\
\mu \text { сар }=160\end{array}$ & 27499.781 & 71578.742 & 110.25 & 24748.27 & 204489.093 & 3.56 & 24576.145 & 201419.301 & 5.47 \\
\hline 25 & $\mu c a p=160$ & 27326.028 & 70236.951 & 4.91 & 24576.952 & 203001.512 & 3.31 & 24576.952 & 203001.25 & 4.03 \\
\hline 26 & $\begin{array}{l}d_{1}=18 \\
d_{2}=20 \\
d_{3}=16 \\
d_{4}=22\end{array}$ & 28320.288 & 47600.381 & 143.13 & 24632.178 & 231632.178 & 2.46 & 24601.877 & 274325.994 & 3.88 \\
\hline 27 & $\begin{array}{l}d_{1}=18 \\
d_{2}=20 \\
d_{3}=16 \\
d_{4}=22 \\
d_{5}=18 \\
d_{6}=19 \\
d_{8}=20\end{array}$ & 28298.939 & 50462.588 & 203.56 & 24688.409 & 231688.409 & 3.09 & 24663.662 & 276969.193 & 12.78 \\
\hline 28 & $\begin{array}{l}d_{3}=16 \\
d_{8}=16 \\
\mu \text { cap }=150\end{array}$ & 27428.819 & 79926.874 & 8.76 & 24907.566 & 200735.341 & 4.56 & 24734.031 & 197614.325 & 5.45 \\
\hline 29 & $\mu c a p=140$ & 27202.79 & 88512.952 & 5.85 & 24913.786 & 207315.029 & 2.82 & 24902.813 & 299336.486 & 12.07 \\
\hline 30 & $\begin{array}{l}d_{3}=16 \\
d_{4}=22 \\
d_{8}=16 \\
\mu \text { cap }=140\end{array}$ & 27373.124 & 90177.001 & 6.73 & 25093.112 & 213420.775 & 3.18 & 24911.856 & 297774.094 & 20.8 \\
\hline
\end{tabular}

criteria methods with the GAMS software. Table 8 compares the values of the first, second, and third objective functions obtained from the three different MODM methods. Figure 3 illustrates the values of the first objective function. Figure 4 shows the values of the second objective function, and Figure 5 represents the values of the CPU time. These graphs show that the solutions provided by MODM methods are different and comparable.

Two sets of analyses were required to select the best MODM methods in the optimality-based analysis. In the first category, the equivalence of the solutions of different methods was tested using the hypothesis test; after ensuring the difference in the mean of solutions, in the second category, the solution proposed to the decision 


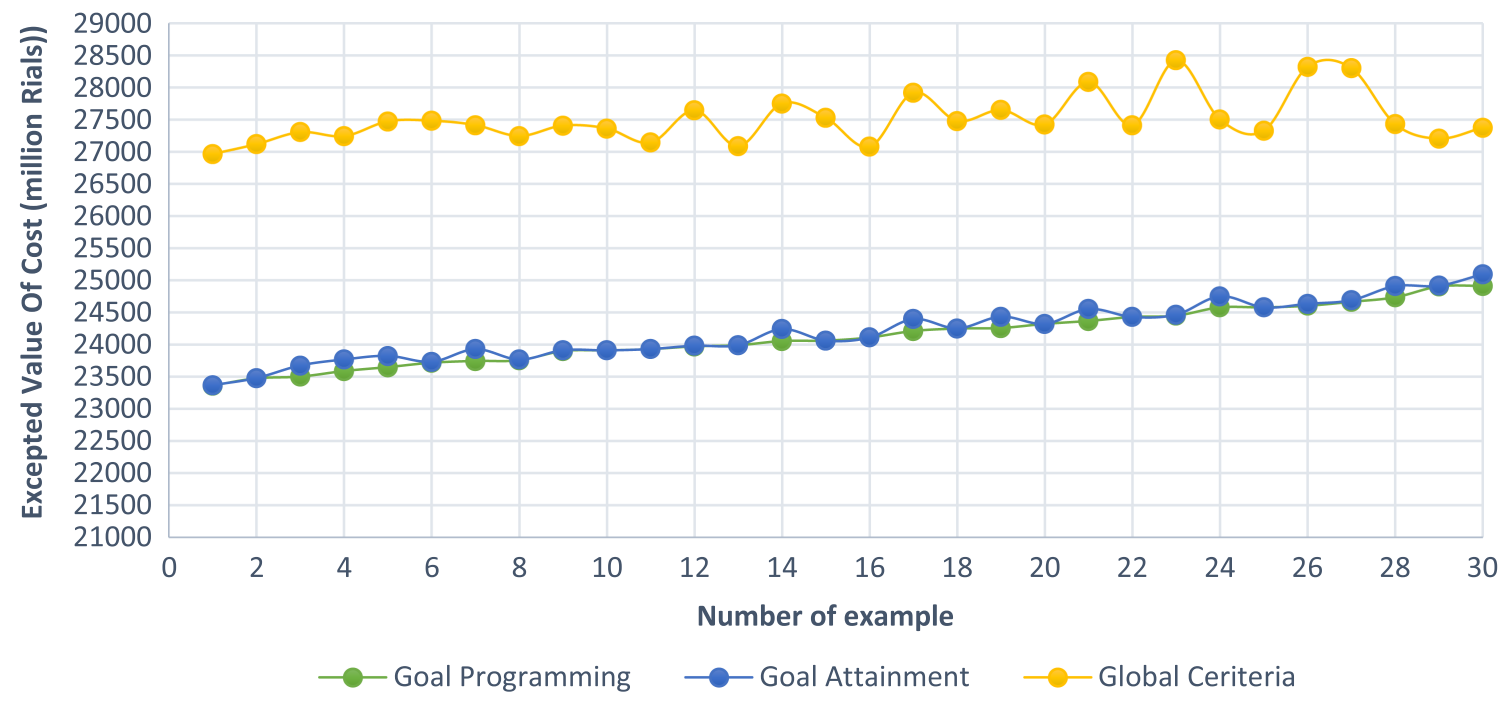

FigurE 3. Comparison of the Goal programming, Goal attainment, and Global criteria methods in terms of the expected value of costs.

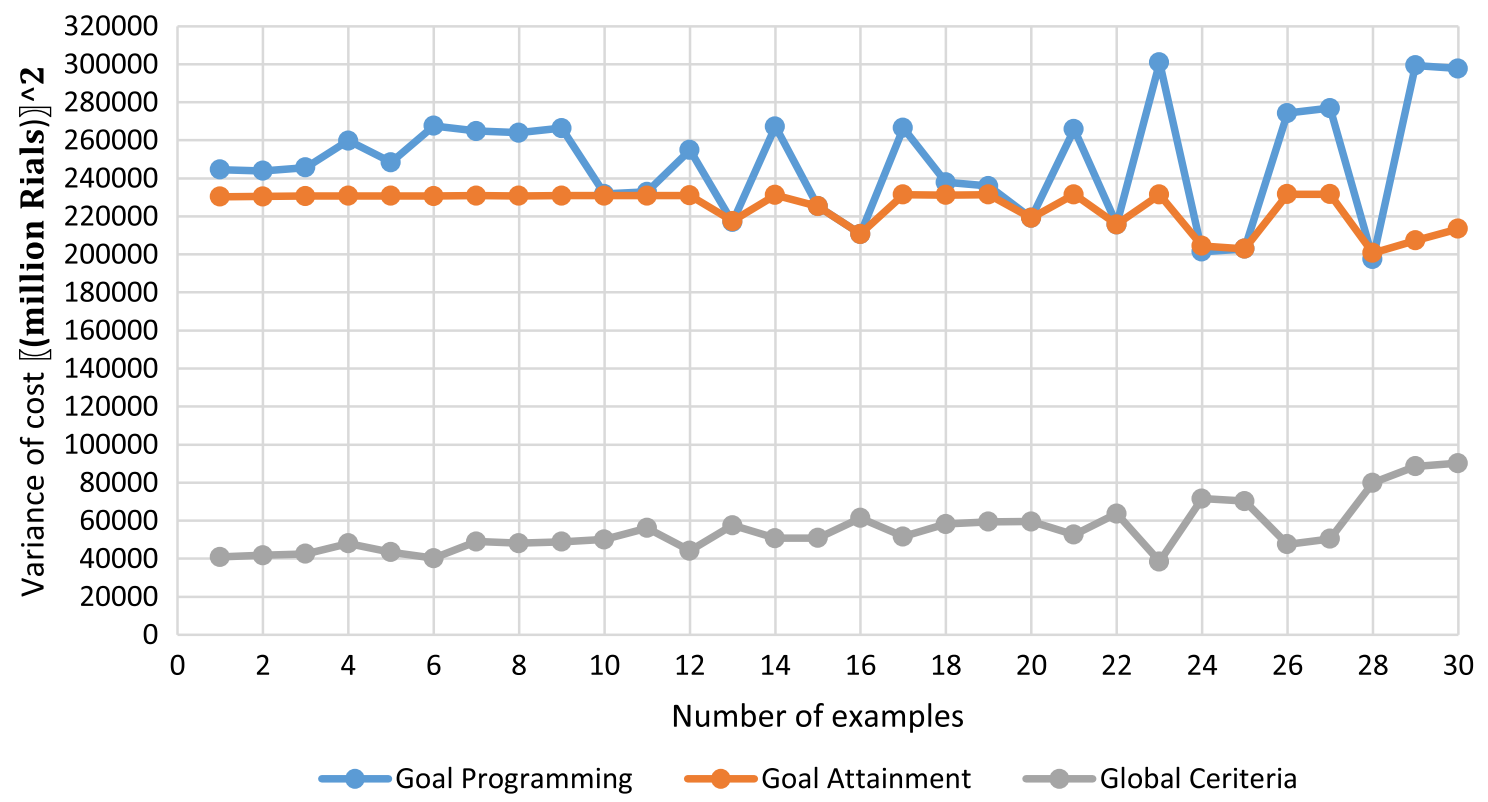

Figure 4. Comparison of the Goal programming, Goal attainment, and Global criteria methods in terms of the variance of costs. 


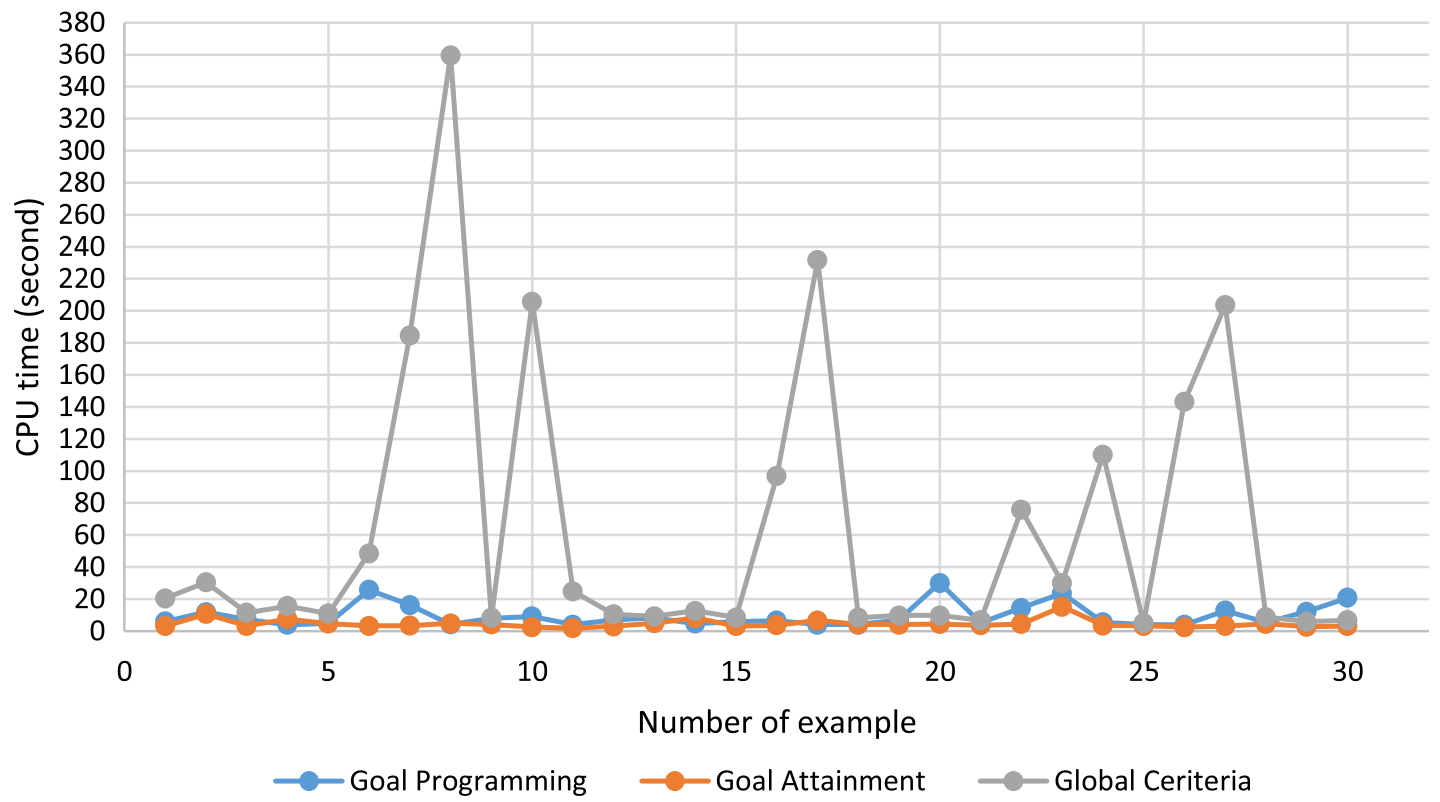

Figure 5. Comparison of the Goal programming, Goal attainment, and Global criteria methods in terms of the $\mathrm{CPU}$ time.

maker was selected using Multi-Attribute Decision Making (MADM) methods. In the following, two groups of optimization-based analyses, including statistical tests and the MADM approach, have been described.

\subsubsection{Statistical tests}

After presenting the methods for solving the proposed two-objective planning model, the performance of them should be examined. To compare and contrast the solutions obtained from each of the proposed MODM methods, there must be a statistically significant difference in the performance of each of them. In this work, two statistical hypothesis tests were implemented, using Minitab 19 software, to prove the difference between the values of the first and second objective functions and the CPU time obtained from each of the solution methods. First, the Welch's test was used to compare the mean of e abnormal societies with the assumption of the inequality of variances. The hypothesis test was considered to be strict to ensure that the mean of the solution obtained by each method would not be equal. Accordingly, the null assumption was that all means were equal $\left(\mu_{\mathrm{GP}}=\mu_{\mathrm{GA}}=\mu_{\mathrm{GC}}\right)$; the alternative hypothesis was that not all means were equal. The significance level was also considered to be 0.5 . Tables 9-14 represent the Welch's test and the confidence interval for the expected value of cost, the variance of cost, and the CPU time. Given the $P$-value and its comparison with the $F$-value, the null assumption was rejected for all objective functions and the CPU time. In fact, the mean of the solution methods was not equal to the concurrent comparison. However, it was still possible to equalize the means of each pair of the solution methods. For this reason, the Games-Howell Simultaneous Test was also used to compare the pair of different MODM methods. Tables 9-14 demonstrate the Games-Howell test. Tables 15 and 16 describe the paired hypothesis test for the expected value of the costs obtained by the proposed solution methods. Based on the interval plot shown in Figure 6, the goal programming and goal attainment did not differ significantly in terms of the value of the first objective function. Other solution methods differed significantly for the expected value of the costs function. Tables 17 and 18 show the paired hypothesis test for the cost variance obtained by the proposed solution methods. The solution methods differed significantly in terms of the second objective function, as shown in Figure 7. Tables 19 and 20 represent the paired hypothesis for the CPU time of the solution methods. As shown in Figure 8, the solution methods differed significantly in terms of the CPU 
TABLE 9. Welch's Test for the value of the costs expected value.

\begin{tabular}{lllll}
\hline \hline Source & Degree of Freedom (DF) Number & DF Den & $F$-Value & $P$-Value \\
\hline Factor & 2 & 57.6535 & 699.76 & 0.000 \\
\hline
\end{tabular}

TABLE 10. Mean, standard deviation, and 95\% confidence interval for the value of the costs expected value.

\begin{tabular}{lllll}
\hline \hline Factor & Number of examples & Mean & Standard deviation & $95 \%$ CI \\
\hline Goal programming & 30 & 24131.0 & 432.0 & $(23969.7 ; 24292.4)$ \\
Goal attainment & 30 & 24201.6 & 443.6 & $(24035.9 ; 24367.2)$ \\
Global criteria & 30 & 27502.1 & 374.4 & $(27362.2 ; 27641.9)$ \\
\hline
\end{tabular}

TABLE 11. Welch's Test for the value of variance of the costs.

\begin{tabular}{lllll}
\hline \hline Source & DF number & DF den & $F$-value & $P$-value \\
\hline Factor & 2 & 52.8048 & 1605.56 & 0.000 \\
\hline
\end{tabular}

TABLE 12. Means, standard deviations, and $95 \%$ confidence intervals for the value of variance of the costs.

\begin{tabular}{|c|c|c|c|c|}
\hline Factor & Number of examples & Mean & Standard deviation & $95 \% \mathrm{CI}$ \\
\hline Goal programming & 30 & 247933 & 28872 & $(237152 ; 258714)$ \\
\hline Goal attainment & 30 & 224612 & 10253 & $(220783 ; 228441)$ \\
\hline Global criteria & 30 & 55203 & 13458 & $(50178 ; 60228)$ \\
\hline
\end{tabular}

time. The conditions for the implementation of the MADM method were provided according to the statistical analysis.

The decision maker (s) can use the proposed statistical method of this research to show the difference between the obtained answers after presenting a suitable mathematical model and solving it with the arbitrary methods. They should expose the generated data from the test problem to the hypothetical tests and a pairwise comparison scheme. The choice of the hypothesis test type strongly depends on the possible distribution of the resulting data. If the null hypothesis is rejected and the inequality of the mean of each solution methods is proved, the decision maker (s) can choose a robust method with different MADM methods.

TABLE 13. Welch's Test for the CPU time.

\begin{tabular}{lllll}
\hline \hline Source & DF number & DF den & $F$-value & $P$-value \\
\hline Factor & 2 & 43.5922 & 12.57 & 0.000 \\
\hline
\end{tabular}




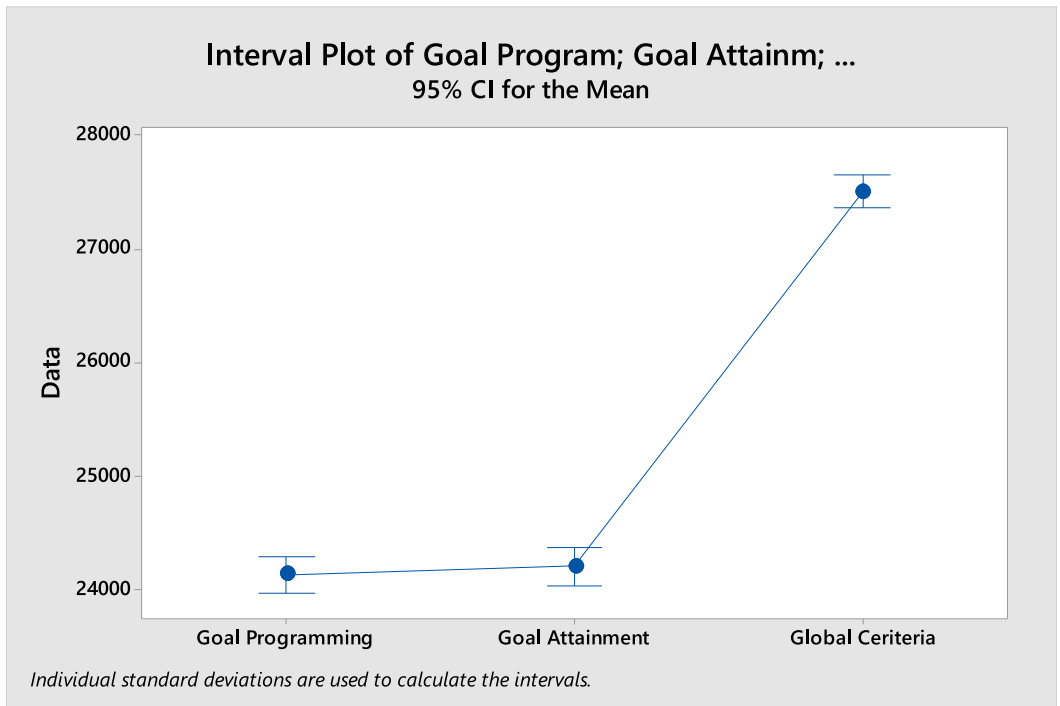

FiguRE 6. Interval plot of goal programming, goal attainment, and global criteria for the value of the costs expected value.

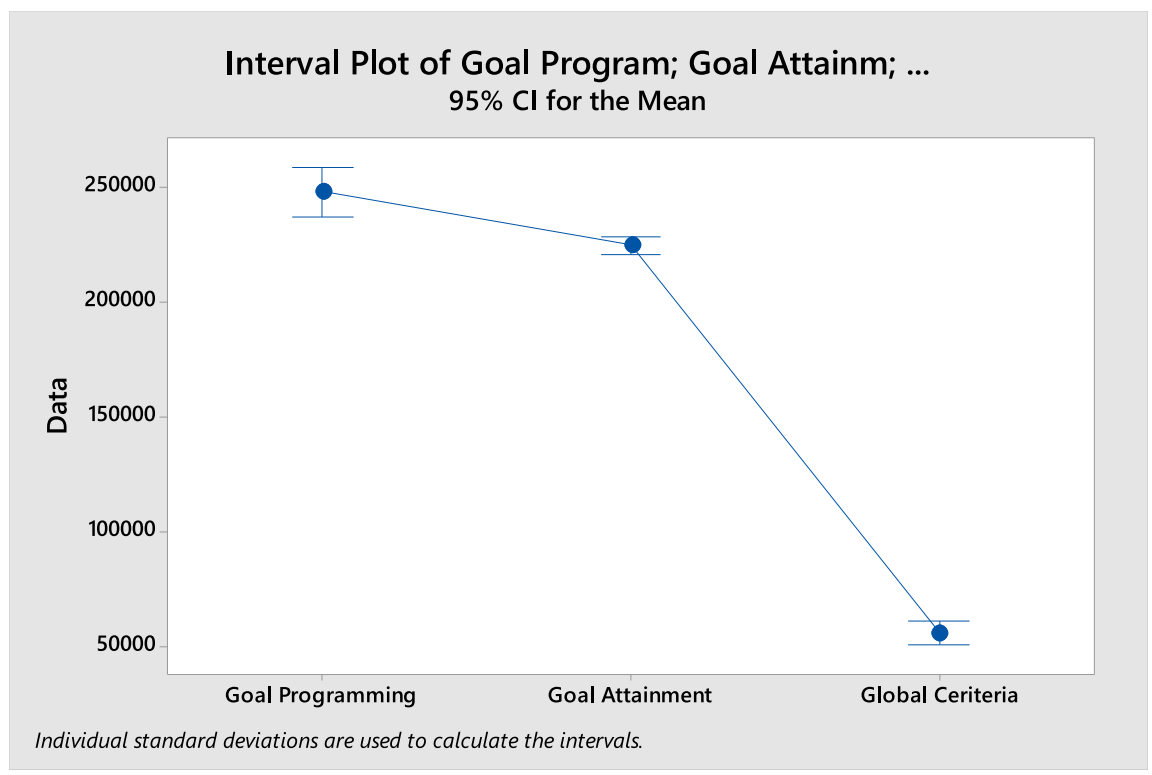

FiguRE 7. Interval plot of goal programming, goal attainment, and global criteria for the value of the costs variance. 
TABLE 14. Mean, standard deviation, and 95\% confidence interval for the CPU time

\begin{tabular}{lllll}
\hline \hline Factor & Number of examples & Mean & Standard deviation & $95 \%$ CI \\
\hline Goal programming & 30 & 9.57 & 7.10 & $(6.91 ; 12.22)$ \\
Goal attainment & 30 & 4.608 & 2.733 & $(3.587 ; 5.628)$ \\
Global criteria & 30 & 63.8 & 89.7 & $(30.3 ; 97.3)$ \\
\hline
\end{tabular}

TABLE 15. Mean and grouping information for the value of the expected value of costs using the Games-Howell method.

\begin{tabular}{lllc}
\hline \hline Factor & Number of examples & Mean & Grouping \\
\hline \hline Global criteria & 30 & 27502.1 & A \\
Goal attainment & 30 & 24201.6 & B \\
Goal programming & 30 & 24131.0 & B \\
\hline
\end{tabular}

Notes. Means that do not share a letter are significantly different.

TABLE 16. Games-Howell simultaneous tests for the differences of means for the value of the costs expected value.

\begin{tabular}{llllll}
\hline \hline $\begin{array}{l}\text { Difference of } \\
\text { levels }\end{array}$ & $\begin{array}{l}\text { Difference of } \\
\text { means }\end{array}$ & $\begin{array}{l}\text { Standard } \\
\text { Error (SE) } \\
\text { of difference }\end{array}$ & $95 \%$ CI & T-value & $\begin{array}{l}\text { Adjusted } \\
P \text {-value }\end{array}$ \\
\hline $\begin{array}{l}\text { Goal Attainment }- \\
\begin{array}{l}\text { Goal Programming } \\
\text { Global Criteria - }\end{array}\end{array}$ & 71 & 113 & $(-201 ; 342)$ & 0.62 & 0.808 \\
$\begin{array}{l}\text { Goal Programming } \\
\text { Global Criteria }-\end{array}$ & 3371 & 104 & $(3120 ; 3622)$ & 32.30 & 0.000 \\
Goal Attainment & 3300 & 106 & $(3046 ; 3555)$ & 31.14 & 0.000 \\
\hline
\end{tabular}

TABLE 17. Mean and grouping information for the value of the variance of costs using the Games-Howell method.

\begin{tabular}{lllr}
\hline \hline Factor & Number of examples & Mean & Grouping \\
\hline Goal programming & 30 & 247933 & A \\
Goal attainment & 30 & 224612 & \multicolumn{2}{c}{ B } \\
Global criteria & 30 & 55203 & C \\
\hline
\end{tabular}

Notes. Means that do not share a letter are significantly different.

\subsection{2. $M A D M$ approach}

After comparing the means of the solutions provided by using different methods, it is now the time to choose the best method. In this paper, a MADM method called Simple Additive Weighting (SAW) [27] was used to select the appropriate method. In the SAW method, the first step for decision-making is the formation of the decision matrix. In the decision matrix, the rows represent the MODM methods (options) and the columns show the objective functions and the CPU time (criteria). Also, each element of the decision matrix is the mean of 
TABLE 18. Games-Howell simultaneous tests for the differences of means for the value of the variance of costs.

\begin{tabular}{|c|c|c|c|c|c|}
\hline $\begin{array}{l}\text { Difference of } \\
\text { levels }\end{array}$ & $\begin{array}{l}\text { Difference of } \\
\text { means }\end{array}$ & $\begin{array}{l}\text { SE of } \\
\text { difference }\end{array}$ & $95 \% \mathrm{CI}$ & $T$-value & $\begin{array}{l}\text { Adjusted } \\
P \text {-value }\end{array}$ \\
\hline $\begin{array}{l}\text { Goal Attainment - } \\
\text { Goal Programming }\end{array}$ & -23321 & 5594 & $\begin{array}{l}(-37007 \\
-9635)\end{array}$ & -4.17 & 0.001 \\
\hline $\begin{array}{l}\text { Global Criteria - } \\
\text { Goal Programming }\end{array}$ & -192730 & 5816 & $\begin{array}{l}(-206877 \\
-178583)\end{array}$ & -33.14 & 0.000 \\
\hline $\begin{array}{l}\text { Global Criteria - } \\
\text { Goal Attainment }\end{array}$ & -169409 & 3089 & $\begin{array}{l}(-176857 \\
-161961)\end{array}$ & -54.84 & 0.000 \\
\hline
\end{tabular}

TABLE 19. Mean and grouping information for the value of the CPU time.

\begin{tabular}{lllll}
\hline \hline Factor & Number of examples & Mean & Grouping \\
\hline Global criteria & 30 & 63.8 & A & \\
Goal programming & 30 & 9.57 & \multicolumn{2}{c}{ B } \\
Goal attainment & 30 & 4.608 & & C \\
\hline
\end{tabular}

Notes. Means that do not share a letter are significantly different.

TABLE 20. Games-Howell simultaneous tests for the differences of means for the CPU time

\begin{tabular}{llllll}
\hline \hline $\begin{array}{l}\text { Difference of } \\
\text { Levels }\end{array}$ & $\begin{array}{l}\text { Difference of } \\
\text { means }\end{array}$ & $\begin{array}{l}\text { SE of } \\
\text { difference }\end{array}$ & $95 \%$ CI & $T$-value & $\begin{array}{l}\text { Adjusted } \\
P \text {-value }\end{array}$ \\
\hline $\begin{array}{l}\text { Goal attainment }- \\
\text { Goal programming }\end{array}$ & -4.96 & 1.39 & $\begin{array}{l}(-8.35 ; \\
-1.57)\end{array}$ & -3.57 & 0.003 \\
\hline $\begin{array}{l}\text { Global criteria }- \\
\text { Goal programming }\end{array}$ & 54.2 & 16.4 & $(13.7 ; 94.7)$ & 3.30 & 0.007 \\
\hline $\begin{array}{l}\text { Global criteria }- \\
\text { Goal attainment }\end{array}$ & 59.2 & 16.4 & $(18.8 ; 99.6)$ & 3.61 & 0.003 \\
\hline
\end{tabular}

the solutions obtained from the 30 provided examples.

$$
\begin{aligned}
& F 1 \quad F 2 \quad \text { CPU } \\
& \text { time }
\end{aligned}
$$

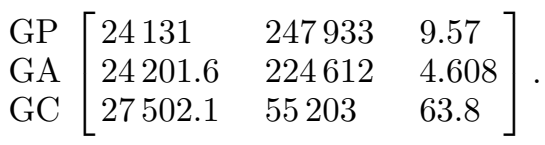

In the next step, the decision matrix should be non-scaled. Normalizing is a process for non-scaling matrices. Then, the weight of each index should be multiplied in the normalized decision matrix. In this study, the weight of each of the criteria (objective functions and the CPU time) could be assumed to be equal. The final SAW matrix is as follows:

$$
\mathrm{SAW}=\left[\begin{array}{lll}
0.33333 & 0.07421 & 0.1605 \\
0.33236 & 0.08192 & 0.33333 \\
0.29247 & 0.33333 & 0.02407
\end{array}\right]
$$




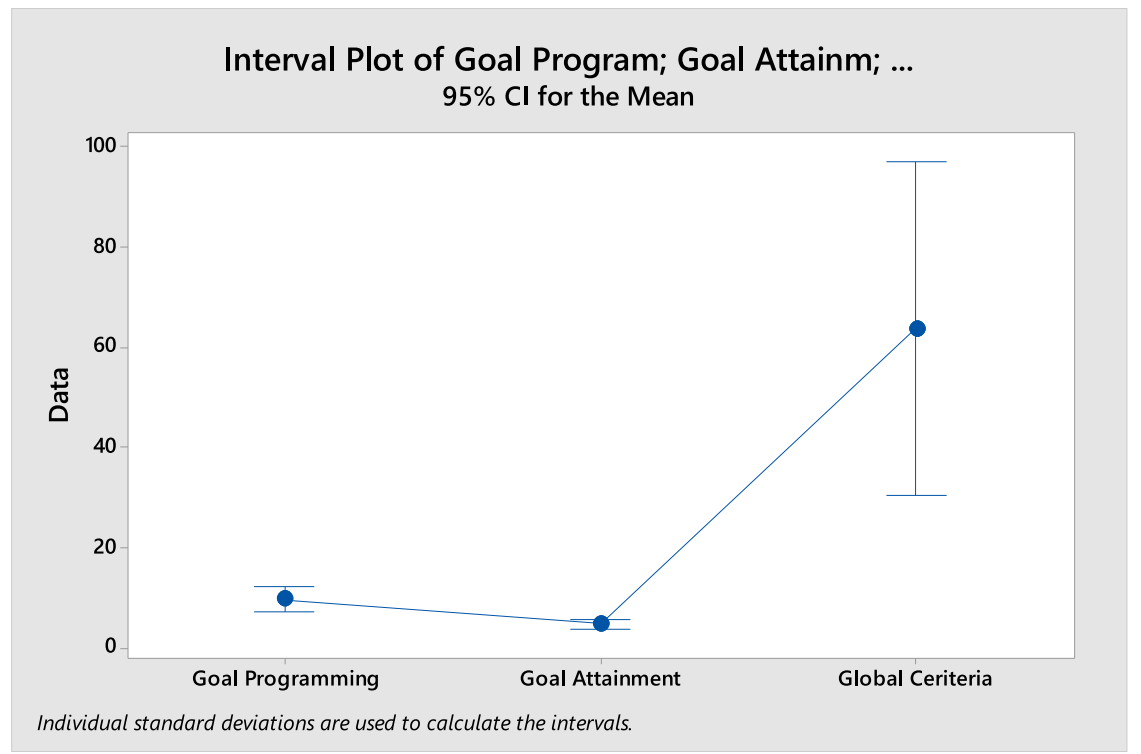

FigURE 8. Interval plot of goal programming, goal attainment, and global criteria for the CPU time.

The score for each of the methods is obtained from the sum of the rows of the decision matrix. The comparison of the scores for each method is as follows:

Score of goal_attainment $>$ Score of global_criteria $>$ Score of goal_programming.

According to the comparison, based on the assumption of the equal importance of all three indicators, the expected value of costs, the cost variance, and the CPU time, the goal-attainment method with the highest score was selected by the analyst.

\section{Conclusion And Future Studies}

In this paper, a new kind of modelling for the design of a green supply chain network was presented with handling the uncertainty involved in some parameters. In this mathematical formulation, two aspects of greenness and handling uncertainty were of particular importance. In order to achieve the greenness goals, for all greenhouse gas emissions, an uncertain upper bound was considered. Also, to control the uncertainty of decisions, a number of parameters were assumed to be uncertain. The resulting stochastic single-objective model was formulated to form a deterministic model as a two-objective one; then the chance constraints of the model were reformulated to be deterministic. To solve the two-objective model, four MODM methods were used to solve 30 different examples. Solutions of various methods were examined by Pareto-based and optimality-based analyses. In the Pareto-based analysis, the $\varepsilon$-constraint method was used and the Pareto front was provided to help decision-makers find the efficient solutions. In the optimal analysis, three methods including goal-programming, goal-attainment, and global criteria were used. In this analysis, to compare different methods and propose the appropriate one to the decision maker, two steps were taken. In the first step, the difference between the means of various methods was verified using the hypothesis test. Then, in the second step, by making the decision matrix and using the SAW method, the proposed method was presented to the decision maker.

For the future studies, suggestions can be made in four categories. These include (1) developing hypotheses, (2) presenting new modelling methods, (3) expanding and improving the way of controlling uncertainty, and (4) providing new solving methods. These suggestions are as follows: 
- considering new objective functions such as minimizing risk, waste product, delivery time, etc.,

- using robust optimization, stochastic scenario-based programming, and hybrid methods for the better control of uncertainties,

- considering fuzzy numbers for some uncertain problem parameters,

- using metaheuristic methods to solve large-scale problems and create the Pareto front by developing analyses, by applying other MODM methods such as Max-Min method, the STEM method, Denovo programming etc., and

- using more advanced approaches such as fuzzy SAW, fuzzy TOPSIS [10,47], TOPPRA [24], etc. to perform the optimality-based analysis.

\section{REFERENCES}

[1] M. Al-Juboori and B. Datta, Optimum design of hydraulic water retaining structures incorporating uncertainty in estimating heterogeneous hydraulic conductivity utilizing stochastic ensemble surrogate models within a multi-objective multi-realisation optimisation model. J. Comput. Des. Eng. 6 (2019) 296-315.

[2] A. Alshamsi and A. Diabat, A reverse logistics network design. J. Manuf. Syst. 37 (2015) 589-598.

[3] F. Altiparmak, M. Gen, L. Lin and T.A. Paksoy, Genetic algorithm approach for multi-objective optimization of supply chain networks. Special Issue on Computational Intelligence and Information Technology: Applications to Industrial Engineering 33rd ICC\&IE - Computational Intelligence \& Information. Comput. Ind. Eng. 51 (2006) 196-215.

[4] A. Azaron, K.N. Brown, S.A. Tarim and M.A. Modarres, Multi-objective stochastic programming approach for supply chain design considering risk. Int. J. Prod. Econ. 116 (2008) 129-138.

[5] H. Badri, S.M.T. Fatemi Ghomi and T.-H. Hejazi, A two-stage stochastic programming approach for value-based closed-loop supply chain network design. Transp. Res. Part E: Logist. Transp. Rev. 105 (2017) 1-17.

[6] S. Baptista, A.P. Barbosa-Póvoa, L.F. Escudero, M.L. Gomes and C. Pizarro, On risk management of a two-stage stochastic mixed 0-1 model for the closed-loop supply chain design problem. Eur. J. Oper. Res. 274 (2019) 91-107.

[7] E. Bottani, T. Murino, M. Schiavo and R. Akkerman, Resilient food supply chain design: modelling framework and metaheuristic solution approach. Comput. Ind. Eng. 135 (2019) 177-198.

[8] M.K. Chalmardi and J.-F. Camacho-Vallejo, A bi-level programming model for sustainable supply chain network design that considers incentives for using cleaner technologies. J. Clean. Prod. 213 (2019) 1035-1050.

[9] A. Charnes, W.W. Cooper and R.O. Ferguson, Optimal estimation of executive compensation by linear programming. Manage. Sci. 1 (1955) 138-151.

[10] S.J. Chen, C.L. Hwang, Fuzzy Multiple Attribute Decision Making: Method and Applications. Springer Verlag, Berlin (1992) 375.

[11] C.L. Chen and W.C. Lee, Multi-objective optimization of multi-echelon supply chain networks with uncertain product demands and prices. Comput. Chem. Eng. 28 (2004) 1131-1144.

[12] S. Chopra and P. Meindl, Supply Chain Management. Strategy, Planning \& Operation, edited by C. Boersch and R. Elschen. In: Das summa summarum des management. Gabler (2007) 265-275.

[13] M.B. Fakhrzad and F. Goodarzian, A fuzzy multi-objective programming approach to develop a green closed-loop supply chain network design problem under uncertainty: modifications of imperialist competitive algorithm: RAIRO: OR 53 (2019) 963-990.

[14] H. Fallah, H. Eskandari and M.S. Pishvaee, Network design for allied supply chains under uncertain conditions: a possibilistic programming approach. Int. J. Fuzzy Syst. 20 (2018) 1857-1871.

[15] A.M. Fathollahi-Fard and M. Hajiaghaei-Keshteli, A stochastic multi-objective model for a closed-loop supply chain with environmental considerations. Appl. Soft Comput. 69 (2018) 232-249.

[16] A.M. Fathollahi-Fard, M. Hajiaghaei-Keshteli and S. Mirjalili, Multi-objective stochastic closed-loop supply chain network design with social considerations. Appl. Soft Comput. 71 (2018) 505-525.

[17] M. Fazli-Khalaf, A. Mirzazadeh and M.S. Pishvaee, A robust fuzzy stochastic programming model for the design of a reliable green closed-loop supply chain network. Human Ecol. Risk Assess. Int. J. 23 (2017) 2119-2149.

[18] H. Golpîra and E.B. Tirkolaee, Stable maintenance tasks scheduling: a bi-objective robust optimization model. Comput. Ind. Eng. 137 (2019) 106007

[19] H. Golpîra, E. Najafi, M. Zandieh and S. Sadi-Nezhad, Robust bi-level optimization for green opportunistic supply chain network design problem against uncertainty and environmental risk. Comput. Ind. Eng. 107 (2017) 301-312.

[20] V. Gonela, D. Salazar, J. Zhang, A. Osmani, I. Awudu and B. Altman, Designing a sustainable stochastic electricity generation network with hybrid production strategies. Int. J. Prod. Res. 57 (2018) 2304-2326.

[21] K. Govindan, H. Soleimani and D. Kannan, Reverse logistics and closed-loop supply chain: a comprehensive review to explore the future. Eur. J. Oper. Res. 240 (2015) 603-626.

[22] G. Guillena, F.D. Mele, M.J. Bagajewicz, A. Espuna and L. Puigjaner, Multi-objective supply chain design under uncertainty. Chem. Eng. Sci. 60 (2005) 1535-1553.

[23] H. Heidari-Fathian and S.H.R. Pasandideh, Green-blood supply chain network design: robust optimization, bounded objective function \& Lagrangian relaxation. Comput. Ind. Eng. 122 (2018) 95-105. 
[24] G. Hêriş, A novel Multiple Attribute Decision Making approach based on interval data using U2P-Miner algorithm. Data Knowl. Eng. 115 (2018) 116-128.

[25] F. Hnaiena, X. Delormeb and A. Dolgui, Multi-objective optimization for inventory control in two-level assembly systems under uncertainty of lead times. Comput. Oper. Res. 37 (2010) 1835-1843.

[26] C.L. Hwang and A.S.M. Masud, Multiple Objective Decision Making Methods and Applications: A State-of-the-Art Survey. Springer-Verlag, Berlin (1979) 676.

[27] C.L. Hwang and K. Yoon, Multiple Attribute Decision Making: Methods and Applications. Springer-Verlag, Berlin (1981) 186.

[28] M. Imran, C.W. Kang and M.B. Ramzan, Medicine supply chain model for an integrated healthcare system with uncertain product complaints. J. Manuf. Syst. 46 (2018) 13-28.

[29] R. Jamshidi, S.F. Ghomi and B. Karimi, Multi-objective green supply chain optimization with a new hybrid memetic algorithm using the Taguchi method. Sci. Iran. 19 (2012) 1876-1886.

[30] A.R. Kalantari-Khalil-Abad and S.H.R. Pasandideh, Green closed-loop supply chain network design with stochastic demand: a new accelerated benders decomposition method. To appear in: Sci. Iran. (2020). DOI: 10.24200/sci.2020.53412.3249.

[31] E. Keyvanshokooh, S.M. Ryan and E. Kabir, Hybrid robust and stochastic optimization for closed loop supply chain network design using accelerated benders decomposition. Eur. J. Oper. Res. 249 (2016) 76-92.

[32] M. Khatami, M. Mahootchi and R.Z. Farahani, Benders' decomposition for concurrent redesign of forward and closed-loop supply chain network with demand and return uncertainties. Transp. Res. Part E: Logist. Transp. Rev. 79 (2015) 1-21.

[33] S. Liu and L.G. Papageorgiou, Multi objective optimization of production, distribution and capacity planning of global supply chains in the process industry. Part of Special Issue: Management Science and Environmental Issues. Omega 41 (2013) 369-382.

[34] E. Mardan, K. Govindan, H. Mina and S.M. Gholami-Zanjani, An accelerated benders decomposition algorithm for a biobjective green closed-loop supply chain network design problem. J. Clean. Prod. 235 (2019) 1499-1514.

[35] A. Mirakhorli, Multi-objective optimization of reverse logistics network with fuzzy demand and return-product using an interactive fuzzy goal programming approach. In: 40th International Conference on Computers and Industrial Engineering (CIE) (2010) 1-6.

[36] S.M.J. Mirzapour Al-e-hashem, H. Malekly and M.B.A. Aryanezhad, Multi-objective robust optimization model for multiproduct multi-site aggregate production planning in a supply chain under uncertainty. Int. J. Prod. Econ. 134 (2011) $28-42$.

[37] A.S. Mohammadi, A. Alemtabriz, M.S. Pishvaee and M. Zandieh, A multi-stage stochastic programming model for sustainable closed-loop supply chain network design with financial decisions: a case study of plastic production and recycling supply chain. Sci. Iran. 27 (2020) 377-395.

[38] A. Mohammed and Q. Wang, The fuzzy multi-objective distribution planner for a green meat supply chain. Int. J. Prod. Econ. $184(2017) 47-58$.

[39] Z. Mohtashami, A. Aghsami and F. Jolai, A green closed loop supply chain design using queuing system for reducing environmental impact and energy consumption. J. Clean. Prod. 242 (2019) 118452.

[40] K.P. Nurjanni, M.S. Carvalho and L. Costa, Green supply chain design: a mathematical modeling approach based on a multiobjective optimization model. Int. J. Prod. Econ. 183 (2017) 421-432.

[41] E. Özceylan, N. Demirel, C. Cetinkaya and E. Demirel, A closed-loop supply chain network design for automotive industry in Turkey. Comput. Ind. Eng. 113 (2016) 727-745.

[42] T. Paksoy, N.Y. Pehlivan and E. Ozceylan, Fuzzy multi-objective optimization of a green supply chain network with risk management that includes environmental hazards. Human Ecol. Risk Assess. Int. J. 18 (2012) 1120-1151.

[43] S.H.R. Pasandideh, S.T.A. Niaki and K. Asadi, Bi-objective optimization of a multi-product multi-period three-echelon supply chain problem under uncertain environments: NSGA-II and NRGA. Inf. Sci. 292 (2014) 57-74.

[44] M.S. Pishvaee, J. Razmi and S.A. Torabi, An accelerated Benders decomposition algorithm for sustainable supply chain network design under uncertainty: a case study of medical needle and syringe supply chain. Transp. Res. Part E: Logist. Transp. Rev. 67 (2014) 14-38.

[45] X. Qu, G. Liu, S. Duan and J. Yang, Multi-objective robust optimization method for the modified epoxy resin sheet molding compounds of the impeller. J. Comput. Des. Eng. 3 (2016) 179-190.

[46] A. Rezaee, F. Dehghanian, B. Fahimnia and B. Beamon, Green supply chain network design with stochastic demand and carbon price. Ann. Oper. Res. 250 (2017) 463-485.

[47] E. Roszkowska and D. Kacprzak, The fuzzy saw and fuzzy TOPSIS procedures based on ordered fuzzy numbers. Inf. Sci. 369 (2016) 564-586.

[48] R. Ruiz-Femenia, G. Guillen-Gosalbez, L. Jimenez and J.A. Caballero, Multi-objective optimization of environmentally conscious chemical supply chains under demand uncertainty. Chem. Eng. Sci. 95 (2013) 1-11.

[49] R. Sadeghi Rad and N. Nahavandi, A novel multi-objective optimization model for integrated problem of green closed loop supply chain network design and quantity discount. J. Clean. Prod. 196 (2018) 1549-1565.

[50] C.N. Samuel, U. Venkatadri, C. Diallo and A. Khatab, Robust closed-loop supply chain design with presorting, return quality and carbon emission considerations. J. Clean. Prod. 247 (2020) 119086.

[51] D.P. Song, J.X. Dong and J. Xu, Integrated inventory management and supplier base reduction in a supply chain with multiple uncertainties. Eur. J. Oper. Res. 232 (2014) 522-536.

[52] Y.-C. Tsao, V.-V. Thanh, J.-C. Lu and V. Yu, Designing sustainable supply chain networks under uncertain environments: fuzzy multi-objective programming. J. Clean. Prod. 174 (2018) 1550-1565.

[53] P. Tsiakis, N. Shah and C.C. Pantelides, Design of multi-echelon supply chain networks under demand uncertainty. Ind. Eng. Chem. Res. 40 (2001) 3585-3604. 
[54] M. Varsei and S. Polyakovskiy, Sustainable supply chain network design: a case of the wine industry in Australia. Omega-Int. J. Manage. Sci. 66 (2017) 236-247.

[55] Y. Wang, T. Lu and C. Zhang, Integrated logistics network design in hybrid manufacturing/remanufacturing system under low-carbon restriction. In: LISS 2012. Springer Berlin Heidelberg (2013) 111-121.

[56] M. Yavari and M. Geraeli, Heuristic method for robust optimization model for green closed-loop supply chain network design of perishable goods. J. Clean. Prod. 226 (2019) 282-305.

[57] G. Zhang, J. Shang and W. Li, Collaborative production planning of supply chain under price and demand uncertainty. Eur. J. Oper. Res. 215 (2011) 590-603.

[58] L. Zhen, L. Huang and W. Wang, Green and sustainable closed-loop supply chain network design under uncertainty. J. Clean. Prod. 227 (2019) 1195-1209.

[59] M. Zohal and H. Soleimani, Developing an ant colony approach for green closed-loop supply chain network design: a case study in gold industry. J. Clean. Prod. 133 (2016) 314-337. 